\title{
Modelling monsoons: understanding and predicting current and future behaviour
}

Book or Report Section

Accepted Version

Turner, A. G., Sperber, K., Slingo, J. M., Meehl, G., Mechoso, C. R., Kimoto, M. and Giannini, A. (2011) Modelling monsoons: understanding and predicting current and future behaviour. In: Chang, C.-P., Ding, Y., Lau, G. N.-C., Johnson, R. H., Wang, B. and Yasunari, T. (eds.) The global monsoon system: research and forecast, 2nd edition. World scientific series on Asia-Pacific weather and climate, 5. World Scientific/WMO, London Singapore New Jersey, pp. 421-454. ISBN 9789814343404 Available at http://centaur.reading.ac.uk/4344/

It is advisable to refer to the publisher's version if you intend to cite from the work. See Guidance on citing. 
All outputs in CentAUR are protected by Intellectual Property Rights law,

including copyright law. Copyright and IPR is retained by the creators or other copyright holders. Terms and conditions for use of this material are defined in the End User Agreement.

\section{www.reading.ac.uk/centaur}

\section{CentAUR}

Central Archive at the University of Reading

Reading's research outputs online 


\section{Modelling Monsoons: \\ Understanding and Predicting Current and Future Behaviour}

Andrew Turner ${ }^{1}$, Kenneth Sperber ${ }^{2}$, Julia Slingo ${ }^{3,1}$, Gerald Meehl ${ }^{4}$,

C. Roberto Mechoso ${ }^{5}$, Masahide Kimoto ${ }^{6}$ and Alessandra Giannini ${ }^{7}$

${ }^{1}$ NCAS-Climate, Walker Institute for Climate System Research, University of Reading

${ }^{2} \mathrm{PCMDI}$, Lawrence Livermore

${ }^{3}$ Met Office, Exeter

${ }^{4}$ NCAR, Boulder

${ }^{5}$ UCLA Atmospheric and Oceanic Sciences

${ }^{6}$ CCSR, University of Tokyo

${ }^{7}$ IRI for Climate and Society - The Earth Institute at Columbia University 


\section{Abstract}

The global monsoon system is so varied and complex that understanding and predicting its diverse behaviour remains a challenge that will occupy modellers for many years to come. Despite the difficult task ahead, an improved monsoon modelling capability has been realized through the inclusion of more detailed physics of the climate system and higher resolution in our numerical models. Perhaps the most crucial improvement to date has been the development of coupled ocean-atmosphere models. From subseasonal to interdecadal timescales, only through the inclusion of air-sea interaction can the proper phasing and teleconnections of convection be attained with respect to sea surface temperature variations. Even then, the response to slow variations in remote forcings (e.g. El Niño-Southern Oscillation) does not result in a robust solution, as there are a host of competing modes of variability that must be represented, including those that appear to be chaotic. Understanding the links between monsoons and land surface processes is not as mature as that explored regarding air-sea interactions. A land surface forcing signal appears to dominate the onset of wet season rainfall over the North American monsoon region, though the relative role of ocean versus land forcing remains a topic of investigation in all the monsoon systems. Also, improved forecasts have been made during periods in which additional sounding observations are available for data assimilation. Thus, there is untapped predictability that can only be attained through the development of a more comprehensive observing system for all monsoon regions. Additionally, improved parameterizations - for example, of convection, cloud, radiation, and boundary layer schemes as well as land surface processes - are essential to realize the full potential of monsoon predictability. Dynamical considerations require ever increased horizontal resolution (probably to 0.5 degree or higher) in order to resolve many monsoon features including, but not limited to, the Mei-Yu/Baiu sudden onset and withdrawal, low-level jet orientation and variability, and orographic forced rainfall. Under anthropogenic climate change many competing factors complicate making robust projections of monsoon changes. Without aerosol effects, increased land-sea temperature contrast suggests strengthened monsoon circulation due to climate change. However, increased aerosol emissions will reflect more solar radiation back to space, which may temper or even reduce the strength of monsoon circulations compared to the present day. A more comprehensive assessment is needed of the impact of black carbon aerosols, which may modulate that of other anthropogenic greenhouse gases. Precipitation may behave independently from the circulation under warming conditions in which an increased atmospheric moisture loading, based purely on thermodynamic considerations, could result in increased monsoon rainfall under climate change. The challenge to improve model parameterizations and include more complex processes and feedbacks pushes computing resources to their limit, thus requiring continuous upgrades of computational infrastructure to ensure progress in understanding and predicting current and future behaviour of monsoons. 


\section{Introduction}

The majority of the world's population lives in countries that rely on the regular return of the monsoon rains, where future increases in population, with their accompanying stresses on the environment, are most likely to occur. These countries often have semi-arid climates that are highly vulnerable to climate variability and change, particularly in terms of water availability and food security. It is, therefore, imperative to predict future changes in the monsoon with as much skill as possible. Although some monsoon regions feature abundant rains, the strong seasonality in rainfall means that understanding the timing, duration and intensity of monsoons is vital. Furthermore, the seasonal march of the monsoons dominates the global circulation, and the influence of monsoons reaches far beyond their immediate geographical domain.

In May 1994 the World Climate Research Programme (WCRP) organised an international conference on 'Monsoon Variability and Prediction' and the challenge to the modeller represented by monsoons could not be more succinctly put than in the Introduction to the Conference Proceedings:

'Understanding the physical processes that determine the monsoon phenomenon has proved to be a remarkable challenge. The processes are subtle and interactive, involving many components of the climate system, both local to the monsoon and remote from it. However, more than the pure scientific challenge of understanding, our ability to predict variations in monsoons, on timescales of days to years, has extraordinary implications for the economies of tropical countries, and represents one of the most fruitful areas where science and society can, and do, interact.'

Fifteen years later this challenge remains.

a. Basic mechanisms: History of using models to understand monsoons

For more than a century the potential for monsoon prediction has been realised via the occurrence of prior global conditions such as snow cover (Blanford 1884) and pressure variations between the Indian and Pacific Oceans (Walker 1924). These relationships became formalized by Charney and Shukla (1981) who suggested that variations in tropical weather conditions were potentially predictable based on the successful simulation of slowly varying lower boundary conditions. In this vein, many studies have used a modelling framework, ranging from conceptual models to fully coupled general circulation models (GCMs) of the ocean-atmosphere-land system to understand the mechanisms involved in monsoon processes and their prediction. Brief examples only are given here:

i) Sea surface temperature (SST): On the large scale, the well known association between the El Niño-Southern Oscillation (ENSO) and the Asian summer monsoon has been extensively examined, as reviewed in Webster et al. (1998). One such modelling study is Ju and Slingo (1995), who implicated heating over the Maritime Continent region, and associated shifts in the ITCZ and Walker circulation, in communicating remote SST anomalies to Asian monsoon dynamics. Alternatively, ENSO heating may be communicated to the Asian monsoons via an asymmetric Rossby wave mechanism (the socalled atmosphere-warm ocean interaction: Wang et al. 2000, 2003). Mechanisms may also rely on Indian Ocean heat transport in the mixed layer or surface heat exchange (e.g. Loschnigg and Webster 2000 and Lau and Nath 2000 respectively). Associations between ENSO and the American monsoons have also been recognized and modelled (Cazes et al. 2003). 
ii) Snow: The historic hypothesis relating Himalayan or Eurasian snow cover with South Asian monsoon anomalies via perturbations to the large scale meridional temperature gradient was examined by several modelling studies (Yasunari et al. 1991; Shen et al. 1998; Becker et al. 2000 amongst others). Most modelling studies separate out the dominant influence of ENSO by prescribing climatological SST. Warming of the Tibetan Plateau has been shown to affect East Asian summer monsoon rainfall via Rossby wave forcing (Wang et al. 2008a). Jhun et al. (2004) have also used GCM experiments to test the positive correlation between autumn snow-forcing in the Siberian High region on the East Asian winter monsoon.

iii) Soil moisture: Consideration of surface conditions other than SST is necessary to form a complete understanding of monsoon systems. Soil moisture, through its coupling of the atmosphere and land surface, has the potential to facilitate local interactions on short timescales (Webster et al. 1998) providing rapid feedbacks on precipitation. Early model studies such as Walker and Rowntree (1977) and Shukla and Mintz (1982) examined the impact of wet and dry soil conditions (for the Sahara and India/Southeast Asia respectively). Recent studies suggest that vegetation processes contribute significantly to set the continental-scale features of the South American monsoon system (Xue et al. 2006).

iv) Orography: Invariant surface conditions also play an important role in the modelled representation of the mean state. The influence of the East African Highlands on the meteorology of the African continent and Indian Ocean was described, in the simple primitive equation model of Rodwell and Hoskins (1995) and also a full atmosphere GCM (AGCM) in Slingo et al. (2005), as essential for the correct positioning of the cross-equatorial flow and consequent distribution of soil moisture and precipitation over Africa and the Indian Ocean region. The Tibetan Plateau is also fundamental to the monsoon climates of South and East Asia through its mechanical and thermal forcing (e.g. Wu et al. 2007). Recent work has also shown the importance of orography for the correct placement of local precipitation features within the South American monsoon (Grimm et al. 2007).

Such studies have been useful for identifying the essential mechanisms and processes for monsoon systems, and to make reliable predictions and larger scale projections. Other broader works involving cooperation between modelling groups have also been beneficial.

\section{b. Basic predictability and projections: History of model studies}

The results from the TOGA Monsoon Experimentation Group (MONEG; WCRP 1992, 1993) and from the Atmospheric Model Intercomparison Project (AMIP; Sperber and Palmer 1996) showed that the simulation of the interannual variation in Indian monsoon rainfall is a demanding test for an atmospheric GCM. In terms of Indian rainfall, for example, the predictive skill of the participating GCMs was limited, although the models showed much more predictive skill when assessed in terms of the interannual variation of the broad-scale monsoon circulation. The goal of providing skilful seasonal forecasts for the monsoon still eludes us. In part this is due to the lack of air-sea interaction in the AMIP experimental design, in which SST is prescribed as the lower boundary condition. In reality, such SST anomalies result from air-sea interaction. As such, AMIP models often represent positive rather than inverse relationships between precipitation and local SST, e.g. in the South China 
Sea or Bay of Bengal (Wang et al. 2004). In addition we do not yet have a clear idea of how predictable the system is likely to be, or how much the apparently chaotic behaviour of the intraseasonal variability may limit that predictability (Sperber et al. 2000).

Numerous approaches to assessing monsoon predictability exist. One approach is dynamical seasonal predictability in which sets of observed (and slightly perturbed) initial conditions are used as the starting point for predicting specific observed seasons. Alternatively, ensembles of multi-decadal or multi-century simulations are made under present-day and future scenarios. In this latter approach one is not making forecasts for a given observed year, rather one evaluates the statistics of variability to discern the possible impact of anthropogenic forcing (e.g. IPCC). We next discuss general findings of these approaches for investigating monsoon predictability; more details for each monsoon system are given in Sections 2-6.

\section{i) APCC/CliPAS, DEMETER, and PROVOST results}

Dynamical seasonal predictability is an evolving branch of forecasting that challenges models to the extreme (Kirtman and Pirani 2008). Retrospective skill has been assessed using ensembles of seasonal hindcasts in which the predictability is assumed to be due to slowly varying boundary conditions (e.g. SST). Experiments have been performed under the auspices of APCC/CliPAS (The Asian-Pacific Economic Cooperation [APEC] Climate Center [APCC]/Climate Prediction and its Application to Society [CliPAS]; Wang et al. 2009), DEMETER (Development of a European Multimodel Ensemble System for Seasonal to Interannual Prediction; Palmer et al. 2004), and PROVOST (Prediction of climate variations on seasonal to interannual timescales; Doblas-Reyes et al. 2000). Together these projects encompass both Tier-2 and Tier-1 experiments. In the former case an SST forecast is made, typically persistence of observed anomalies into the future (though in idealized studies the SST from a coupled model may be used) and then these SSTs are used as the lower boundary condition in hindcasts made with an atmospheric GCM. Tier-1 hindcasts are made using fully coupled ocean-atmosphere GCMs (hereafter AOGCMs). Results from these two methodologies suggest: (1) Tier-1 systems are essential for capturing monsoon variability, especially for the Asian domain, while Tier-2 AGCMs forced by prescribed SST are inadequate for monsoon seasonal prediction (Wang et al. 2005). This is because, for example, the Indian Ocean is not just a slave to ENSO, but air-sea interaction there serves to modify the direct forcing from the Pacific Ocean; (2) Monsoon prediction skill of surface air temperature is superior to that of precipitation; (3) Skill is mainly due to ENSO, but competing large-scale interactions preclude a unique ENSO-monsoon signal, even in terms of the sign of anomalies. Monsoon predictive skill is virtually absent in nonENSO years; (4) Consistent with earlier results, the multi-model ensemble tends to have greater skill than any of the individual models, especially on seasonal timescales; (5) Assessment of forecasts of intraseasonal (Madden-Julian-type) oscillations has been more limited, mainly highlighting the poor representation of intraseasonal oscillations (ISO) in models as being a limiting factor is attaining the skill suggested from perfect predictability studies.

Despite the present paucity of skill in forecasting monsoons on intraseasonal to interannual timescales, it is anticipated that improved forecasts can be obtained with better models of the climate system. A more accurate representation of intraseasonal variability in models is sure to improve medium-range to monthly forecasts. Meanwhile, reduction of systematic model error through development of better parameterizations, and the improved representation of multi-scale interactions, including land-atmosphere interactions, provides the potential to improve skill. 
ii) Predictions of monsoon behaviour in IPCC assessment results

From the first assessment of the Intergovernmental Panel for Climate Change (IPCC), future monsoon behaviour has been related to the relative heating of land versus ocean. That is, as greenhouse gas concentrations increase and the planet warms, land heats up faster than oceans. This increases the meridional temperature gradient in South Asia (and potentially other regions) and strengthens the monsoon. The IPCC Third Assessment report also noted a possible complication whereby increasing aerosols could act in competition with greenhouse gas forcing. If these aerosol effects are also taken into account, the nature of changes to the monsoon really depends on the future time evolution of aerosols over the monsoon regions. For example, an increase of sulphate aerosols can enhance reflection of solar radiation, thus weakening the heating of the land surface and contributing to weakening of the meridional temperature gradient and a less intense monsoon. The IPCC Third Assessment Report concluded as much, and noted that most of the future emission scenarios show an initial increase of sulphate aerosols over South Asia in the first part of the $21^{\text {st }}$ century, for example, with decreases by the end of the century following likely de-sulphurization of industry and power generation. Therefore, the South Asian monsoon would first weaken slightly and then strengthen later in the century as sulphate aerosol loadings decrease and GHGs continue to increase, with the net effect an increase in meridional temperature gradient and a stronger monsoon (Cubasch et al. 2001).

Studies completed and assessed in the subsequent IPCC Fourth Assessment Report (AR4) note the important distinction between changes to monsoon flow and precipitation. More recent model studies have shown that there is a slight weakening of the Asian monsoon south-westerly inflow but monsoon rainfall is projected to increase due to a combination of increased moisture-holding capacity of the warmer air and the increase in evaporation over the warmer Indian Ocean even while monsoon circulation decreases (Meehl et al. 2007). Since then, studies have begun incorporating the effects of a more diverse range of aerosols, including black carbon.

A key goal of monsoon modelling research is making projections of how short timescale events, such as extremes of precipitation, monsoon depressions and active-break cycles, may change in the future. At present uncertainties in these areas are high, partly because models do not have sufficient resolution to capture the convective processes and weather systems that give rise to these events. The recent IPCC Fourth Assessment Report gave some coverage to projections of rainfall extremes in monsoon climates (Meehl et al. 2007; Christensen et al. 2007) with the general conclusion that climate warming is likely to be associated with increases in the risk of intense precipitation and associated flooding. This may occur even in regions of mean drying (Meehl et al. 2007) due to intensification of individual rainfall events.

A more focused overview of recent modelling efforts for each of the monsoon systems is given below. Section 2 describes the state of current climate simulations of the South Asian monsoon and Section 3 gives an update on its future climate projections. Sections 4,5 and 6 focus on the East Asian summer monsoon, American monsoon systems and the African monsoon, respectively. Section 7 concludes this chapter with an outline of some of the major monsoon modelling challenges. 


\section{South Asian Monsoon: Contemporary climate variability and predictability}

For the mainly agrarian societies of South Asia perturbations in rainfall can mean the difference between feast and famine. The South Asian monsoon tends to be dominated by two timescales of variability that have strong impacts on rainfall over this region: (1) interannual variations sometimes associated with ENSO, and (2) 3060 day intraseasonal oscillations (ISO) that modulate convection and embedded synoptic variations (e.g. cyclones). ENSO is important because it provides a strong boundary forcing that establishes remote teleconnections over the monsoon region and elsewhere, whereas the ISO is important for the onset and active-break cycles of the monsoon.

Due to interannual variations, the standard deviation of seasonal monsoon rainfall anomalies over India is about $10 \%$ of the climatological seasonal mean (e.g. Pant and Rupa Kumar 1997). Though accurate seasonal forecasts can provide the opportunity to ameliorate the possible effects of a deficient monsoon, the impact of intraseasonal events can be catastrophic in causing rainfall departures that can be $70 \%$ below normal for weeks at a time. The chaotic nature of intraseasonal events (Sperber et al. 2000) complicates amelioration efforts since, for example, crop failure can occur if the suppressed convective phase of the intraseasonal oscillation commences soon after seed has been sown. Additionally, the spatial heterogeneity of the rainfall departures associated with the interannual and intraseasonal perturbations challenges our ability to predict regional variations of monsoon rainfall.

\subsection{Interannual variability and ENSO teleconnections}

Seasonal forecasts are currently being made by major numerical weather prediction centres, with emphasis on predicting ENSO (van Oldenborgh et al. 2005). While useful skill in predicting regionally averaged ENSO SST indices extends to 6-12 months, the pattern of SST anomalies is less well represented in the seasonal forecasts, though it is crucial for predicting the monsoon teleconnections. For example, depending on the strength and location of EI Niño SST anomalies, suppressed rainfall over India, due to changes in the Walker circulation, may be overwhelmed by local Hadley circulation perturbations leading to normal or abovenormal rains during El Niño, the reverse of that expected if the ENSO-monsoon teleconnection were the sole forcing of interannual monsoon variations (Slingo and Annamalai 2000). Also, model studies indicate that regional SST influences in the Indian Ocean can temper the robustness of the ENSO-monsoon teleconnection (Annamalai et al. 2005). Additionally, the ENSO-monsoon teleconnection itself waxes and wanes on interdecadal timescales with climate model studies indicating that the weakening of this teleconnection in the late 1990s occurred due to natural variability rather than being due to anthropogenic forcing (e.g. Annamalai et al. 2007; Turner et al. 2007).

Improved skill in seasonal monsoon prediction is attained using coupled oceanatmosphere models since air-sea feedbacks are important for establishing the correct teleconnections (Palmer et al. 2004). Even so, seasonal forecast skill of rainfall is predominantly confined over the ocean, with little skill over the land area of the South Asian monsoon (Wang et al. 2009), especially in non-ENSO years. Thus, even in years of strong boundary forcing the ENSO-monsoon teleconnection does not always provide a unique solution, and predictions in non-ENSO years are even more challenging (Sperber and Palmer 1996). Coupled models also develop systematic biases which can strongly affect the skill of the model to capture monsoon-ENSO teleconnections. Turner et al. (2005) showed that the use of limited area flux adjustment to improve equatorial Pacific SSTs has a substantial impact on monsoon- 
ENSO teleconnections (Fig. 1), by allowing the anomalous heating during El Niño to migrate eastwards away from the West Pacific warm pool and to establish the correct changes to the Walker circulation. These results have emphasised the importance of improving model basic state errors and also suggest that the commonly used approach of removing model bias after the forecast has been made is probably invalid in a system that is clearly not linear.

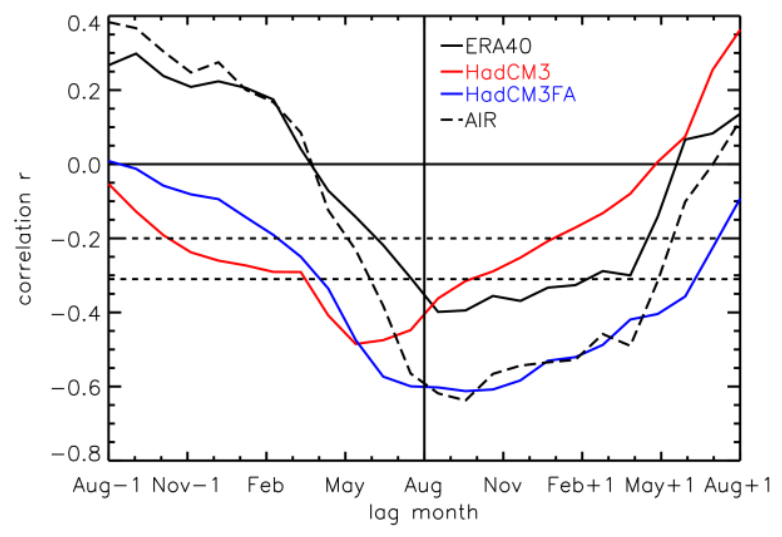

Figure 1: Lag-lead correlations of JJAS All-India rainfall (AIR) with Niño-3 SST anomalies from 100-year current climate simulations of HadCM3 without and with flux adjustment (FA) to improve the mean state of the Indo-Pacific warm pool. Dashed curve shows the All-India gauge dataset correlated with HadISST SST (from Turner et al. 2005).

\subsection{Active/break cycles}

The 30-60 day timescale of ISOs results in extended periods of enhanced and reduced rainfall that are associated with active and break cycles of the monsoon. The duration of the ISO life cycle bridges numerical weather prediction and seasonal/climate timescales. As such, knowledge of the initial state of the atmosphere is required, as is air-sea interaction for forecasting ISOs (Waliser et al. 2006). Figure 2 indicates the potential for 20-30 days of rainfall predictability based on numerical experiments initialized with small perturbations to the initial atmospheric state during different phases of the models ISO (Fu et al. 2007). Compared to earlier predictability studies in which an AGCM was used (Waliser et al. 2003), the use of a coupled model provides approximately one week of additional predictability. In twotiered forecasts, ISO convective anomalies develop too soon since they lock on to the prescribed warm SST anomalies. One-tier forecasts, in which air-sea interaction gives rise to the SST, are more successful since the convection develops in quadrature with warm (cold) SST anomalies that lead (lag) the convection, consistent with observations. These idealized dynamical predictability studies, and the success of empirical/statistical ISO forecasts (e.g. Wheeler and Weickmann 2001; Webster and Hoyas 2004), suggest the huge potential that dynamical predictions of the ISO have for improving monthly and seasonal forecasts. With such potential in mind, experimental intraseasonal forecasts are presently being made in real-time ${ }^{1}$.

\footnotetext{
${ }^{1}$ See: http://www.cdc.noaa.gov/MJO/ and http://www.cpc.ncep.noaa.gov/products/precip/CWlink/MJO/mjo.shtml
} 


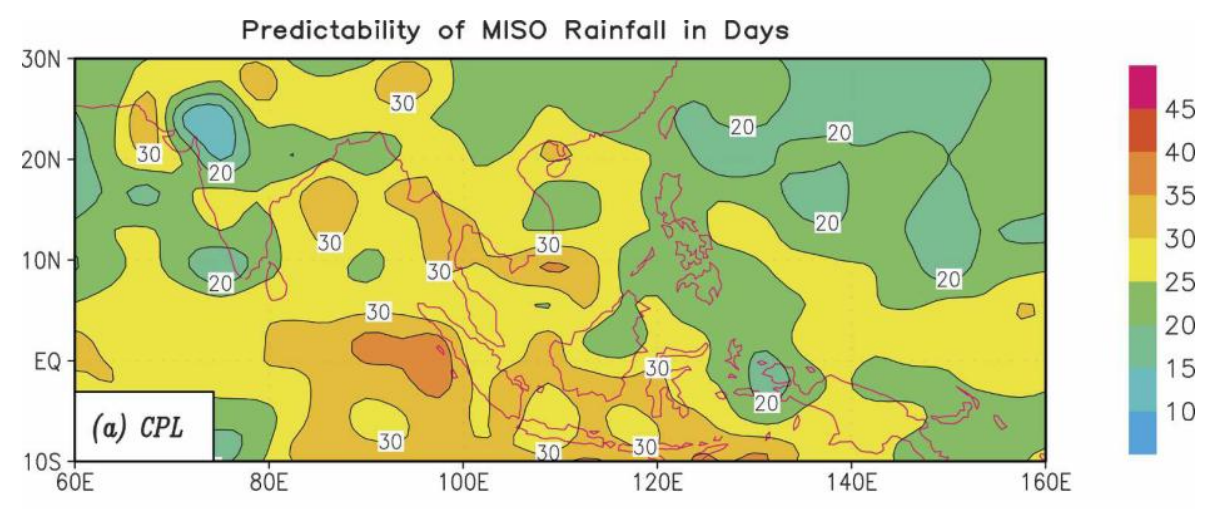

Figure 2: The spatial distribution of ISO-related rainfall predictability in days averaged for all four initial condition phases from the coupled model (after Fig. 9a of Fu et al. 2007).

Issues and evidence of rectification of the intraseasonal variability onto the seasonal mean monsoon have been discussed in Waliser (2006). Observational evidence exists of a common mode of variability that links intraseasonal timescales to interannual variations of the monsoon (Sperber et al. 2000). Additionally, dynamical seasonal predictability hindcasts suggest the importance of correctly projecting the subseasonal modes onto the seasonal mean monsoon (Sperber et al. 2001). However, the leading mode is not linked to slowly varying components of the climate system (e.g. ENSO SST); rather it exhibits chaotic behaviour (Sperber et al. 2000). This chaotic behaviour can compete with the low frequency monsoon-ENSO teleconnection, thus compromising our ability to make seasonal forecasts, even during years of strong boundary forcing.

A further complication to the prospect of monsoon predictability is the presence of a hierarchy of modes/timescales that govern monsoon variability (Annamalai and Slingo 2001). Even so, improvements in our ability to simulate the boreal summer ISO (Sperber and Annamalai 2008) bode well for realizing the potential predictability suggested by the aforementioned idealized ISO predictability experiments. The full potential of dynamical monsoon predictability can only be realized with an improved understanding of the physics of the ISO. To this end a more systematic approach for diagnosing the ISO in models has been proposed (CLIVAR MJO Working Group 2009), and forecast diagnostics are in development with case study hindcast experiments being considered (http://www.usclivar.org/Organization/MJO WG.html).

\section{South Asian Monsoon: Future climate change projections}

\subsection{Future climate scenarios}

There are two aspects of monsoon activity that are relevant to how the South Asian monsoon may react in a future climate with increased greenhouse gases. One relates to the simple property of the climate system whereby land areas, with their lower heat capacity, warm faster than oceans in transient climate change scenarios with increasing greenhouse gas concentrations. Since a major driver of the South Asian Monsoon is the regional-scale land-sea temperature contrast, or more accurately meridional tropospheric temperature gradients, a situation where land is warming faster than ocean should strengthen this gradient and thus intensify the monsoon. Indeed, the IPCC Third Assessment Report notes this response to increasing $\mathrm{CO}_{2}$.

More recent work has expanded on those earlier studies and looked at the relationship between the dynamics of the monsoon and its precipitation in a future warmer climate. The emerging picture is a bit more complicated than the earlier 
results. For example, Tanaka et al. (2005) studied a multi-model dataset consisting of 15 coupled atmosphere-ocean GCMs to show a weakening of the dynamical monsoon circulation of $14 \%$ by the late $21^{\text {st }}$ century compared to the late $20^{\text {th }}$ century. Another possible consequence of tropical climate change related to increases of GHGs is the relatively large tropospheric warming in the tropics compared to higher latitudes. This thermodynamic change was credited with reducing the meridional temperature gradients in the South Asian region in an eight member multi-model ensemble, thus producing weakened monsoon circulation (Ueda et al. 2006).

The second major response of the system to consider when examining possible future changes of the South Asian Monsoon relates to the increase of SST in the Indian Ocean. This produces greater evaporation, an increased moisture source for the monsoon, and a consequent increase in monsoon rainfall (Douville et al. 2000; Meehl and Arblaster 2003; May 2004). A related response is a northward shift of the surface monsoon winds that carry moisture and rainfall farther north over South Asia, but with an associated weakening of the monsoon southwesterlies (Ashrit et al. 2003, 2005; Turner et al. 2007).

Perhaps the major uncertainty in future projections of the mean South Asian monsoon lies in the effects of aerosols. Early studies of monsoon changes included either no aerosols (GHGs only), or only the direct effects of sulphate aerosols. The IPCC Third Assessment Report noted that including sulphate aerosols could act in competition with the increasing temperature gradient by reflecting sunlight over South Asia, reducing land warming compared to the ocean, and thus weakening the monsoon. This additional aspect was examined further in the IPCC Fourth Assessment Report (Meehl et al. 2007). More recent studies have examined the effects of black carbon aerosols on the monsoon. Meehl et al. (2008) showed that the recent decline of observed South Asian monsoon rainfall is likely connected to the increase in black carbon aerosols over South Asia. The result has been a change in the seasonality of the South Asian rainfall, with an increase in premonsoon rainfall and a decrease during the monsoon summer. This was attributed to a mechanism known as the "elevated heat pump" (Lau et al. 2006) whereby the black carbon aerosols both reflect sunlight during the pre-monsoon, cooling the Indian subcontinent and north Indian Ocean, and absorb solar radiation to heat the lower troposphere. This heated air is advected northward over the Tibetan Plateau, contributing to the elevated heat source and enhancing on-shore flow driven by the meridional tropospheric temperature gradient, with consequent increases in premonsoon rainfall. However, the black carbon aerosols rain out with the approach of the monsoon season, diminishing the elevated heat source and weakening the meridional temperature gradient. Additionally, the Indian subcontinent is left cooler from the effects of aerosol-reflected solar radiation, the monsoon flow weakens, the equatorial Indian Ocean is warmer than the north Indian Ocean, and monsoon rainfall over South Asia consequently decreases while precipitation increases over the ocean regions farther south.

The possible future effects of ongoing increases in black carbon aerosols over South Asia were highlighted by Ramanathan et al. (2005) who showed, for a business as usual black carbon aerosol scenario, a decrease of monsoon season rainfall of roughly $25 \%$ by around 2050 . These recent studies with the combined effects of sulphate and black carbon aerosols highlight the seasonal and longer term changes that may be in store for the South Asian monsoon resulting from the effects of increased GHGs and aerosols.

Another key point of interest for future behaviour is whether the monsoon will become more or less variable. Most results to date have indicated the former, with projected increases in monsoon interannual variability in a future warmer climate $\mathrm{Hu}$ 
et al. 2000; Meehl and Arblaster 2003). This has been shown to come from two possible sources. Hu et al. (2000) analyzed an AOGCM that showed future El Niño events would become more variable, and thus transmit that enhanced variability to the South Asian monsoon via the large-scale east-west circulation. However, Meehl and Arblaster (2003) used analyses of AOGCM results and sensitivity experiments to show that the future monsoon variability would increase independent of any change to ENSO variability, simply because of warmer mean tropical Pacific and Indian Ocean SSTs. That is, the nonlinear relationship between SST and evaporation dictates that for a given interannual fluctuation of tropical Pacific SSTs, with a warmer base state the evaporation response would increase, thus enhancing interannual evaporation and resulting precipitation variability even if the El Niño variability stayed the same as today. These studies indicate that a future increase of South Asian monsoon interannual variability is a relatively robust result.

\subsection{ENSO-monsoon teleconnections}

In Section 2.1 the importance of capturing monsoon-ENSO teleconnections for describing monsoon interannual variability has been noted and a key question under climate change is whether this teleconnection may change. Ashrit et al. (2003) documented a relatively robust dynamical connection between the tropical Pacific and the South Asian monsoon that changed little in a future warmer climate, but there can be different results depending on the index used, whether it is a dynamical index or monsoon area-averaged rainfall. For example, in Turner et al. (2007), the dynamical teleconnection between ENSO and the South Asian monsoon is strengthened in a future warmer climate whereas an area-averaged monsoon rainfall index and its teleconnection with ENSO either weakened somewhat or stayed about the same.

Although there have been some suggestions of a weakening of the monsoon-ENSO teleconnection in recent decades, possibly due to global warming (e.g. Krishna Kumar et al. 1999), more recent studies have indicated that this may be more indicative of decadal-timescale variability, since this relationship appears to have been strengthening again (Annamalai et al. 2007). The role of natural low-frequency variability in the monsoon-ENSO teleconnection appears to be considerable (e.g. Ashrit et al. 2003; Annamalai and Liu 2005; Turner et al. 2007), thus complicating efforts to attribute changing teleconnections to anthropogenic warming.

\subsection{Active/break cycles and extreme events}

Initial attempts to predict changes to monsoon intraseasonal variability used AGCMs in climate change time-slice integrations forced by results from coupled models. These allow a reasonably high-resolution focus on particular regions while remaining relatively computationally inexpensive. In one such study, May (2004) used a highresolution version of ECHAM4 to make projections of the probability of heavy rain events, the magnitude of extreme precipitation events and return times between 30 year events over India. The likelihood of extremes and their magnitude were both found to increase, particularly over the Arabian Sea. Douville (2005) cautions however that AGCM timeslice experiments cannot properly capture the true response of regional features over South Asia to global warming due to their lack of oceanatmosphere coupling (see Section 2.2).

While Dairaku and Emori (2006) used an AGCM to suggest that increases in extreme precipitation over South Asia had their origins in dynamic effects, there may be strong mechanistic differences between A- and AO-GCMs. Turner and Slingo (2009a) used the HadCM3 coupled GCM to show not only that extremes of monsoon 
precipitation were increasing due to mainly thermodynamic effects, but that these increases were very predictable based on the degree of warming and the expected increases in moisture from the Clausius-Clapeyron relationship (see Fig. 3). Even when comparisons are made across the fully coupled models in the $3^{\text {rd }}$ Coupled Model Intercomparison database (hereafter CMIP3), large uncertainties in changes to tropical precipitation extremes abound (Kharin et al. 2007). One potential source of this uncertainty lies in the type of convective parameterization employed (Turner and Slingo 2009b). There are also diverse projections in the spatial distribution of changes to extremes across South Asia, which Turner and Slingo (2009a, 2009b) suggest are model dependent and can only be relied upon when the projected pattern of mean change is more certain.

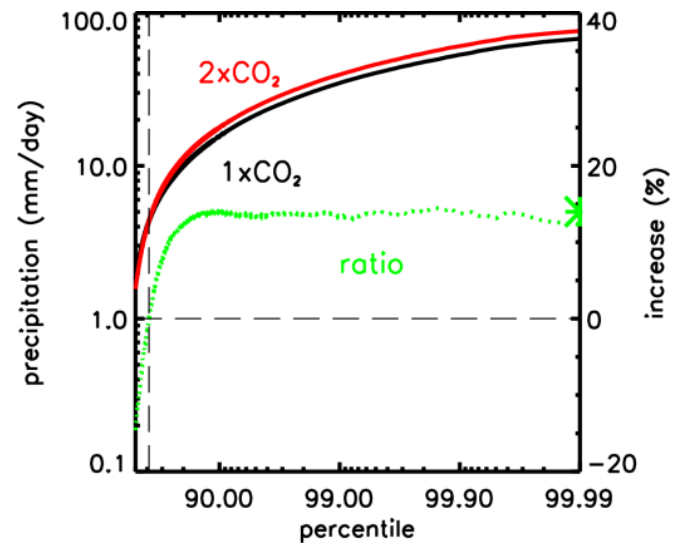

Figure 3: Levels of precipitation over India associated with upper percentile extremes at $1 \times \mathrm{CO}_{2}$ (black) and $2 \mathrm{XCO}_{2}$ (red) in HadCM3. Their ratio is plotted as percentage increase (green). The maximum percentage increase shown closely matches that expected (marked with an asterisk) due to warming over the Arabian Sea region $=2.09 \mathrm{~K} \times 6.05 \% / \mathrm{K}=12.6 \%$. After Turner and Slingo (2009a).

Given the coarse resolution of GCMs and their inherent poor representation of tails of the rainfall distribution (e.g. Sun et al. 2006), downscaling techniques have been utilized to improve confidence in projections. Dynamical downscaling, involving the nesting of regional climate models (RCMs) within GCM output, provides one such method. As reported in Christensen et al. (2007), large increases in precipitation extremes are projected for the end of the $21^{\text {st }}$ century, particularly over the west coast and west central India (Rupa Kumar et al. 2006), regions where mean increases were also concentrated.

Few authors have attempted to make future projections of monsoon active-break cycles (whose timing, frequency and duration are of immense importance to agriculture) - indeed no evidence was presented in the IPCC AR4 in this regard. Mandke et al. (2007) examined 6 models in the CMIP3 archive using a precipitation index and found inconsistent responses even among the same model to different forcing scenarios. Of particular concern is the ability of coarse resolution GCMs to simulate the finer details of the spatio-temporal evolution of active-break events. However, Turner and Slingo (2009a) demonstrated that even relatively coarse resolution GCMs such as HadCM3 could show evidence of details such as the convective dipole (equatorial Indian Ocean versus Indian subcontinent) and northward propagation of ISOs. Neither study reported changes to the duration or frequency of break events, but Turner and Slingo (2009a) do suggest that both active and break events may become more intense in the future. 


\section{East Asian Summer Monsoon}

\subsection{Contemporary climate variability}

The East Asian Summer Monsoon (EASM) is quite different in nature from the South Asian Monsoon which is dominated by the north-south land-sea contrast. The EASM, however, is characterized by an east-west orientated rain band that extends from southern China to Japan, referred to as the Mei-Yu/Baiu rain band in this review. The rain band characterizes the pre-summer rainy season, and its northward shift or disappearance brings hot mid-summer climate to the East Asian countries. It is generally agreed that the formation and variability of this rain band can only be understood as a combination of tropical and extratropical influences (e.g. Ninomiya and Murakami 1987).

So far, most state-of-the-art GCMs have difficulties in realistically simulating this rain band (Kang et al. 2002). In many cases it has been difficult to reproduce appropriate east-west orientation and north-south concentration of the band, its swift northward migration during the onset, not to mention its intraseasonal and/or mesoscale variability. These difficulties may arise from the complex features of the Mei-Yu/Baiu rain band: its narrow north-south scale, frontal structure characterized not just by temperature but more by moisture contrast, possible control both from the upper-air subtropical jet (and its meander) and low-level south-westerly moisture flow on the western edge of western north Pacific subtropical high, and the possible role of subsynoptic-scale disturbances in bringing convectively active precipitation (Ninomiya 2004).

Recent attempts at high-resolution atmospheric modelling, however, have made considerable progress in overcoming some of these difficulties. Consistent with the horizontal resolution sensitivity study of Sperber et al. (1994), Kawatani and Takahashi (2003) have shown that their T106 ( 110km grid) AGCM successfully reproduced the east-west oriented Mei-Yu/Baiu rain band. The latter authors noted that attaining a realistic strength and vertical structure of the simulated rain band was sensitive to a tuning of gravity wave drag which is strongest over the Tibetan Plateau and controls the downstream structure of the subtropical jet. Kimoto (2005) demonstrated that a high-resolution (T106) version of their coupled atmosphereocean GCM has considerable advantage in reproducing realistic frequency distribution of strong rain events in comparison to lower resolution (T42 $\sim 280 \mathrm{~km}$ ) version. Kobayashi and Sugi (2004) tested a range of AGCM resolutions from T42 to T213 and noted that while seasonal mean rainfall featured a similar distribution at all resolutions, synoptic scale events and tropical cyclones were much better simulated at T213. A very high-resolution AGCM of $20 \mathrm{~km}$ mesh run by the Japan Meteorological Agency (JMA) / Meteorological Research Institute (MRI) reproduces a realistic onset and retreat of the rain band, which enables investigations of changes in Mei-Yu/Baiu period under the influence of anthropogenic climate change (Kusunoki et al. 2006). The same model also shows a much improved simulation of orographic rainfall and distribution of extreme events (Kitoh and Kusunoki 2008).

It is known that tropical to midlatitude variability of the East Asian summer monsoon is much affected by convective activity over the tropical north-western Pacific, where many GCMs have difficulties (Kang et al. 2002). Arai and Kimoto (2007) note an advantage of resolution in reproducing the high-latitude anomaly centre of the tripolar pattern. More detailed studies need to be carried out for better understanding of mechanisms of East Asian monsoon variability, both forced and natural, in which models with high resolution and improved convection should play a crucial role. 


\subsection{Decadal and longer-term variations}

Decadal and longer-term variations also need to be considered when examining change in the EASM. While Hirota et al. (2005) identified a recent (1979-2003) trend that resembles the tripolar pattern, it is well known that centennial time series of monsoon precipitation show large interdecadal variations (e.g. Goswami 2006). Wu and Wang (2002) noted changes in the relationship between the EASM and ENSO since the late 1970s, particularly over northern China and Japan during ENSO decay. Whilst the Indian monsoon-ENSO relationship has tended to weaken during this period, enhancement has occurred for the EASM (Wang et al. 2008b). Recently, Lei et al. (2009) have reported resemblance between simulated natural modes of precipitation variability and those of observed decadal variations over China. Furthermore, based on model simulations, Arai et al. (2009) note that the impact of anthropogenic aerosol on the long-term precipitation trend may not be negligible. Clearly, understanding climate variability and change in East Asia warrants better modelling capability, in terms not only of resolution, but also of improved physical processes.

\subsection{Future climate scenarios}

Kimoto (2005) has shown that the mean change of the large-scale East Asian summer monsoon in a T106 GCM is characterized by a 'tripolar pattern' (Fig. 4b), which consists of three upper-air anomaly centres in the East Asian longitude belt between $120^{\circ} \mathrm{E}$ and $150^{\circ} \mathrm{E}$ : one over the north-eastern Eurasian continent around $60^{\circ} \mathrm{N}$, another over the latitude of $30-40^{\circ} \mathrm{N}$, and one in the subtropics around $15-20^{\circ} \mathrm{N}$. Under global warming, the first and third centres have positive height change tendencies, and the second (middle) centre has a negative tendency in the GCM. Arai and Kimoto (2007) note that this simulated pattern has considerable resemblance to the observed (Fig. 4a), as well as simulated, mode of interannual variability, which has been frequently discussed in the literature. Both Kimoto (2005) and Arai and Kimoto (2007) emphasize the dual role played by extratropical and tropical factors; the former is related to meanders in the summertime polar-frontal jet that develops on the border between warm Eurasian Continent and relatively cool Arctic Ocean. The meanders in the polar-frontal jet (or so-called Okhotsk High) activity can be subject to springtime continental warming (Kodera and Chiba 1989; Arai and Kimoto 2005; Kimoto 2005).
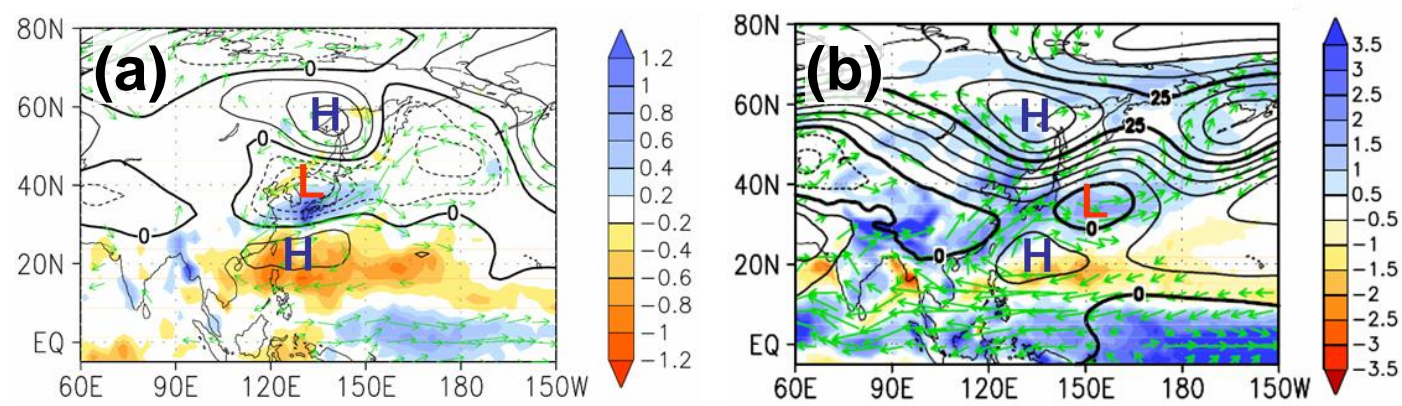

Figure 4: The tripolar pattern in East Asian summer monsoon variability. (a) Regression coefficients against JJA-mean observed precipitation (percentage) anomalies for western Japanese stations during years 1951-2002. The NCEP/NCAR reanalysis data is used for height and winds and 1979-1998 CMAP data for precipitation. (b) JJA climate change as simulated by an ensemble of T106 AGCM runs (Kimoto 2005). Contours are for 500hPa geopotential height anomalies $(\mathrm{m})$, shading for precipitation $(\mathrm{mm} /$ day) and vectors for 850hPa wind anomalies $(\mathrm{m} / \mathrm{s})$.

The resemblance between the natural variability and forced climate change, along with possible roles of extratropical and tropical influences on the East Asian tri-polar 
pattern, makes its study scientifically challenging. Kosaka and Nakamura (2006) investigated the equatorward half of the tripolar pattern as a classical Pacific-Japan (PJ) teleconnection (Nitta 1987) and noted that it can be interpreted as a natural dynamical mode arising from the three-dimensionally varying summertime monsoon basic flow. Hirota (2008, personal communication) gives an extended interpretation dealing also with the high-latitude features.

\section{American Monsoon Systems}

\subsection{Contemporary climate variability and ENSO impacts}

The warm season flow over the Americas shows the classical monsoon-type surface low pressure/upper-level anticyclone, intense low-level inflow of moisture from the ocean, seasonal increase in regional precipitation, and large-scale convergence zones with ascent to the east and descent to the west over the ocean (NoguésPaegle et al. 2002; Higgins et al. 2003; Vera et al. 2006a; Mechoso et al. 2005). We refer to the warm season circulations in tropical North and South America as monsoon systems (NAMS and SAMS, respectively).

Precipitation during NAMS has a relative minimum in the warm season along the Sierra Madre Oriental and the Caribbean (mid-summer drought or MSD) in association with seasonal displacements of the ITCZ in the eastern Pacific.

Contemporary general circulation models capture the large-scale circulation features of the American monsoons, but fail to produce realistic simulations of the statistics of regional precipitation patterns and how they are modulated by the large-scale circulation. The models show important differences in the simulated precipitation in regions of complex terrain, monthly evolution, and diurnal cycle of precipitation (Gutzler et al. 2003; Ma and Mechoso 2007). These difficulties are particularly clear in the timing and intensity of the MSD and South Atlantic Convergence Zone (SACZ).

Tropical intraseasonal oscillations such as the MJO modulate a number of different weather phenomena affecting the American monsoon systems, such as tropical cyclones and easterly waves, Gulf of California surges, and SACZ intensity. NAMS and SAMS rainfall variability on different timescales have a continental-scale pattern showing an out-of-phase relationship between precipitation anomalies in the core regions and those to the northeast and southwest, respectively. In the southwestern U.S, wet (dry) conditions during winter are often followed by stronger (weaker) NAMS events. This is consistent with a significant local impact of anomalous land surface conditions.

Warm and cold ENSO events tend to be associated with weaker and stronger SAMS, respectively. SST anomalies in the eastern equatorial Pacific during the northern winter are significantly and positively correlated with precipitation anomalies in the southwestern U.S. Therefore, such SST anomalies can be linked with either drought or flood in the Great Plains of North America during the following summer through lasting impacts on local land surface conditions in the southwestern U.S, and the continental-scale pattern of NAMS rainfall variability mentioned above. Cold (warm) SST anomalies in the tropical North (South) Atlantic have been linked with stronger SAMS rains. An association has also been reported between SSTs higher than $29^{\circ} \mathrm{C}$ in the Gulf of California and anomalously strong NAMS events in Arizona. Observational evidence indicates the springtime snowpack modulates the amplitude of the NAMS (Ropelewski et al. 2004); no similar relationship has been proposed, to our knowledge, for the SAMS.

Recent research has identified a major feature of convection over tropical South America on intraseasonal timescales, which could be thought of as the counterpart to 
South Asian monsoon breaks (Ma and Mechoso 2007). Anomalous SAMS precipitation shows a continental-scale dipole-type pattern with centres in northwestern and central/south-eastern Brazil, indicating a stronger (weaker) SACZ. In central Amazonia, anomalous winds at low-levels change direction from predominantly easterly to westerly for periods longer than three days (see schematic in Fig. 5). The observed diurnal cycle in precipitation during the convection (or wind) regimes shows an early-afternoon maximum over Amazonia. Depending on location, there can be a second early-morning (nocturnal) maximum when low-level winds are persistently from the east. This sensitivity of the diurnal cycle of precipitation to wind direction is largely missed by current GCMs.

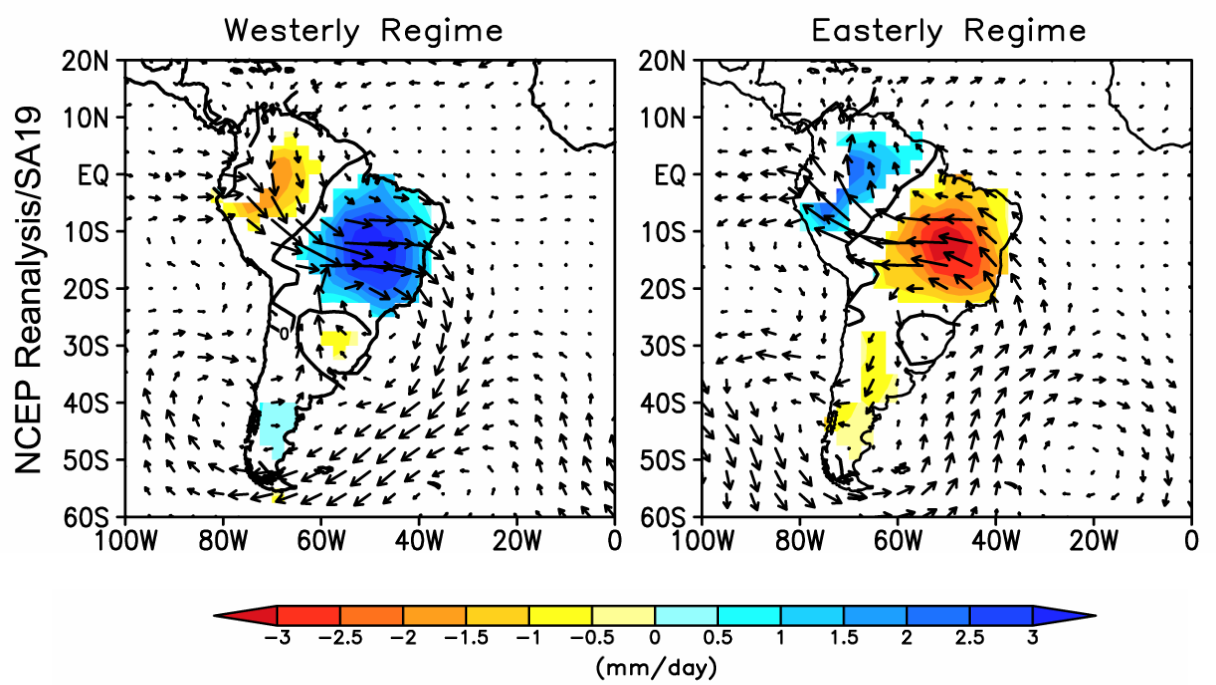

Figure 5: Schematic showing mean precipitation and wind anomalies (contours and vectors, respectively) corresponding to the westerly and easterly regimes in Amazonia (left and right). Data from NCEP/NCAR reanalysis for the period 1949-2003 (Kalnay et al. 1996).

Intense work is currently dedicated to improve the model, data-assimilation and datagathering components of numerical climate prediction systems in order to increase forecast skill, particularly in the warm season. Models use increasingly higher resolution to better resolve orographic and regional effects of the complex terrain that makes up the NAMS and SAMS regions. Regarding model physics, areas targeted for improvement include the parameterization of convection, boundary layer, and land surface processes. The need to enhance local observing systems has been demonstrated. Additional work is dedicated to explore and mine new potential sources of predictability. In this regard, accurate forecasts of MJO activity could lead to significant improvements in the skill of warm season precipitation forecasts over the Americas.

\subsection{Predictability and prediction}

On seasonal to interannual timescales, the potential for enhanced predictability resides in the possible effects on the atmosphere of slowly varying surface conditions. The influence on the NAMS and SAMS of varying conditions over oceans and land reported so far is somewhat marginal. Consistently, predictability studies with global models generally obtain modest levels of seasonal-mean precipitation skill over the NAMS and SAMS domains. Nevertheless, predictive skill of warm season rainfall in the Americas is useful in the tropics (Goddard et al. 2003). ENSO effects contribute to higher predictability in the north and south of the SAMS domain. Zamboni et al. (2009) show that, in southeastern South America during the warm season over the period 1959-2000, the long-range rainfall forecasts by the coupled 
AOGCMs in the DEMETER project show poor skill in general, but higher skills in ENSO years.

The importance of atmosphere-land interactions increases towards the end of the dry season, when surface heating weakens the static stability of the overlying atmosphere resulting in favorable conditions for the wet season onset. In view of the marginal sensitivity of NAMS and SAMS to oceanic anomalies, one could argue that anomalous surface conditions are more important during the wet season onset. The relative roles of remote forcing (particularly SST) and regional land surface forcing in the development, maintenance and decay of NAMS and SAMS are a matter of current debate (Grimm 2003).

Lag composites of geopotential height anomalies at $850 \mathrm{mb}$ prior to the establishment of the wind regimes in Amazonia (Fig. 5) show the development of structures in the South Pacific that resemble the principal modes of variability in that region, which are usually referred to as the Pacific South American (PSA) patterns. This finding suggests that links exist between the wind regimes and the modes of intraseasonal variability over the South Pacific and over South America. Thus, it is proposed that the wind regimes over Amazonia are associated with low-frequency variability in the extratropical circulation. The potential predictability of this feature is being explored.

An important contributor to the low prediction skill of the American monsoons is the scarcity of observations in key geographic locations. For the NAMS, the observing system has severe limitations over parts of México, the intra-Americas Sea region, and the tropical oceans in general. NCEP model-based data assimilation systems including sounding data collected during the field campaign of the North American Monsoon Experiment (NAME) indicate a significant and beneficial impact of the added information at low levels in the atmosphere and mainly in the core monsoon region of northwestern México, southwestern U.S., and Gulf of California low-level jet (Mo et al. 2005). Similarly, studies at CPTEC including data from the South American Low-Level Jet Experiments (SALLJEX) suggest improvements in the lowlevel wind and moisture transport in the LLJ region (Cavalcanti and Herdies 2004). Improvement was also reported in the prediction of a mesoscale convective system (MCS) event that occurred during the SALLJEX. Additional data impact studies are under way in order to suggest efficient improvements of the observing systems.

\subsection{Future climate scenarios}

The CMIP3 models (from the most recent IPCC report) indicate that precipitation generally increases in the American monsoon regions due to anthropogenic effects. The monsoonal precipitation over parts of the NAMS domain (Mexico and Central America), however, is projected to decrease. In regard to SAMS, model projections include precipitation increase over southeastern subtropical South America, and a precipitation decrease in all seasons along the southern Andes (Vera et al. 2006b). 


\section{African Monsoons}

\subsection{Contemporary climate variability and ENSO impacts}

Africa, with the exception of its extremities, is a tropical continent: its climate is defined by the alternation of wet and dry seasons following the passage of the sun ${ }^{2}$. This behaviour is most evident in West Africa - the bulge extending into the Atlantic Ocean north of the equator. As land surface temperatures reach $30^{\circ} \mathrm{C}$ in the Sahara desert in July-August, precipitation migrates northward into the Sahel. This migration is not smooth, rather it is characterized by a sudden jump from its location along the Guinea coast (Sultan and Janicot 2003; Gu and Adler 2004) ${ }^{3}$. The same behaviour is not as pronounced south of the equator due to the greater mitigating influence of the surrounding oceans: but even in this case the rainfall peak, which occurs in February, is located equatorward of maximum temperature.

The role of global sea surface temperatures in shaping the potential predictability of rainfall over tropical Africa has been thoroughly assessed in both observational and modelling studies. ENSO is known to affect west (Janicot et al. 1996; Ward 1998; Giannini et al. 2003), eastern-equatorial (Ogallo 1989; Schreck and Semazzi 2004) and southern Africa (Mason 2001). The expected outcome is complicated by the influence of other regional phenomena. Indeed hindcasts of the West African monsoon show very little skill when multi-model ensembles are used (Wang et al. 2009), compared to adjacent oceanic regions. Still, there is skill in operational seasonal forecasts at one-month lead time in the Sahel (Goddard et al. 2003). For the three month seasons from JJA to ASO, the skill quantified by a positive Ranked Probability Skill Score (RPSS) is comparable to that of OND or NDJ forecasts for eastern equatorial Africa, and slightly better than OND to JFM forecasts for southern Africa (Barnston et al. 2009). In the Sahel one needs to remove the pronounced interdecadal variation to clearly isolate the impact of ENSO for below-average rainfall during warm events, and above-average rainfall during cold events. In eastern equatorial Africa, wet conditions during El Niño typically occur only in conjunction with a warming of the western equatorial Indian Ocean (Goddard and Graham 1999; Black et al. 2003; Giannini et al. 2008). In southern Africa the 1997-1998 El Niño did not result in the expected drought due to the opposing tendency of a persistent circulation pattern in the adjacent southern Atlantic region (Reason and Jagadheesha 2005; Lyon and Mason 2007).

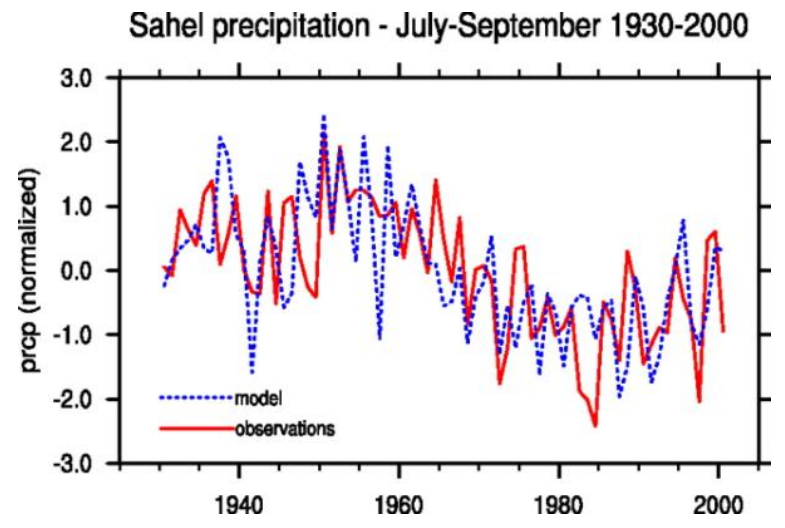

Figure 6: Variability in rainfall in the Sahel $\left(10-20^{\circ} \mathrm{N}, \quad 20 \mathrm{~W}-40^{\circ} \mathrm{E}\right)$ in observations (solid red) and ensemble mean of 9 simulations run with the NASA Seasonal to Interannual Prediction Project (NSIPP) model developed at Goddard Space Flight Center (Bacmeister et al. 2000) forced by observed SST (dashed blue). Taken from Giannini et al. (2003).

\footnotetext{
${ }^{2}$ The reader interested in teasing out the relative roles of land and ocean in the seasonal cycle over Africa and the adjacent tropical Atlantic Ocean is referred to a series of modelling studies by Biasutti et al. (2003, 2004, 2005).

${ }^{3}$ This jump is consistent with inertial instability theory (Nicholson and Webster 2007).
} 
A pronounced interdecadal variation has characterized the Sahel (the poleward margin of the northern hemisphere summer monsoon or equatorward margin of the Sahara) during the second half of the $20^{\text {th }}$ century (Lamb 1982; Nicholson 1993; Trenberth et al. 2007). Anomalously wet conditions in the 1950s and 1960s gave way to progressively drier conditions, which bottomed out in the mid-1980s. This decadal variation is well captured in state-of-the-art atmospheric models forced with observed SST (Giannini et al. 2003, as in Fig. 6; Lu and Delworth 2005; Tippett 2006), and in at least one instance of a coupled ocean-atmosphere simulation of $20^{\text {th }}$ century climate (Held et al. 2005). A continental-scale analysis of annual mean rainfall (Giannini et al. 2008) found that significant traces of such decadal variability, associated with a warming of the equatorial and southern oceans contrasted by cooling of the mid-latitude North Atlantic and Pacific (Folland et al. 1986), are ubiquitous in West Africa, but are also present at the margin of the southern African monsoon across Zambia and Zimbabwe.

A similar SST pattern has recently been attributed to external forcing in the $20^{\text {th }}$ century simulations obtained from the CMIP3 database (Ting et al. 2009). In this context the apparent recovery of seasonal rainfall totals in the Sahel since the mid1980 s is explained by the increased influence of an internal mode of variability of the coupled ocean-atmosphere system. The present phase of the Atlantic Multidecadal Oscillation (Hoerling et al. 2006) is countering the drying associated with warming of the equatorial Indian Ocean (Giannini et al. 2003, 2005; Bader and Latif 2003; Hagos and Cook 2008). The recovery of Sahel rainfall (Fig. 6) contrasts a negative trend identified in merged satellite-gauge rainfall products in eastern equatorial Africa (Schreck and Semazzi 2004).

Statistical and dynamical descriptions of the intraseasonal character of the West African monsoon have been the object of many studies since the seminal work of Burpee (1972) on African Easterly Waves. These studies have shown that the seasonal mean character of rainfall accumulation is reflected in the frequency of events rather than in their magnitude (Lebel et al. 2003), i.e. that a dry season is one with fewer, rather than weaker rainfall events, and that such conditions have clear associations with regional and global circulation patterns such as equatorial Kelvin and Rossby waves, and monsoonal surges (Matthews 2004; Mounier et al. 2007; Mekonnen et al. 2008; Moron et al. 2008a, 2008b).

\subsection{Future climate scenarios}

While apparently complex, these features on intraseasonal to decadal timescales connect the continental climates of Africa to climatic changes at the global scale. Whether any of the changes already witnessed, not only in seasonal rainfall totals, but also in the intraseasonal distribution of rain events, can be attributed to anthropogenic influences remains a topic of heightened interest given the vulnerability of African societies to weather and climate (Boko et al. 2007; West et al. 2008). Ascertaining the origin of recent trends at a continental scale (e.g. as done globally by Alexander et al. 2006) may also prove helpful in clarifying the mechanisms underlying projections of future climate change, which for this continent, as well as for most other tropical areas, are still fraught with great uncertainty (Christensen et al. 2007). This is despite the progress made in conceptual models depicting expectation (Allen and Ingram 2002; Neelin et al. 2003; Held and Soden 2006). 


\section{Future modelling challenges}

A grand challenge of monsoon modelling is to be able to inform end-users, local communities and policy makers of locally precise predictions for the monsoon regions, not only on seasonal timescales but also in the high frequency characteristics of interest, rainfall distribution etc. This applies not only to forecasting in the present day but also in climate projections of the coming decades and beyond. The work presented here has shown that, in some cases, there is still difficulty in simulating the local characteristics of monsoon precipitation and their evolution, perhaps related to deficiencies in the representation of orography, convective parameterization, or biases in the mean state itself. It is not clear, therefore, that such models can make accurate time-averaged projections of rainfall characteristics on all but the large scale. Despite the recent progress outlined in this chapter, several key issues have emerged which pose challenges for the direction of future monsoon modelling research. These challenges affect the realistic simulation of observed features and concern primarily: (1) the processes more faithfully captured by adequate coupling between the ocean and atmosphere; (2) improvements to be made by increasing model resolution, particularly in the representation of scale interactions, and (3) missing physical processes that were not previously considered.

\section{a. Ocean-atmosphere coupling}

The importance of ocean-atmosphere coupling for correctly representing monsoon processes on many timescales has been increasingly demonstrated. On short timescales, insufficient coupling has been implicated in the poor representation of monsoon ISO (e.g. Kemball-Cook and Wang 2001), and its improvement has been shown to increase possible lead times in monsoon ISO forecast (Fu et al. 2007). While the current global coupled GCMs do show some evidence of northward propagation associated with monsoon ISO (Sperber and Annamalai 2008; Lin et al. 2008) their phase speeds in particular are deficient. The frequency at which information is exchanged between the atmosphere and ocean can also impact the representation of variability. For example, Bernie et al. (2005) demonstrated that by increasing the coupling frequency to every three hours from once per day, up to $90 \%$ of the daily variance in SST associated with the passage of the MJO could be modelled. At the longer timescales necessary for seasonal forecasting, coupled airsea interactions continue to be important. For the Asian summer monsoon for example, Bracco et al. (2007), amongst others, have shown full coupling to a dynamic ocean in the Indian and west Pacific Oceans as necessary for representing the sign of the teleconnection with ENSO. Also related is the relationship between SST and local precipitation in various tropical oceans. In forced SST experiments, rainfall anomalies are positively correlated with SST in regions such as the South China Sea, however in reality, feedbacks to the ocean make some of these observed correlations negative (Wang et al. 2004). Thus Tier-1 systems are required for accurate dynamical seasonal prediction via both local and remote forcing. However, coupled models still contain large systematic biases in their mean state which are detrimental to seasonal prediction (Turner et al. 2005), for which other factors including model resolution and missing processes have a role to play.

\section{b. Model resolution and scale interactions}

The high resolution modelling work outlined in this chapter has suggested that an improved representation of several monsoon characteristics can be achieved, such as the seasonal cycle, the structure and progression of the Mei-Yu/Baiu rain band during monsoon onset, representation of tropical cyclones, and the effects of 
orography on precipitation distribution. One of the challenges of increasing model resolution, especially in the horizontal, is the importance of correctly representing processes on the scales we are resolving, which may hitherto have been parameterized on the sub-grid scale. Higher resolution regional models nested within global GCMs have also been used to some extent in this regard; however they are ultimately still forced by boundary conditions from a coarse resolution model that exhibits its own inherent biases. Other studies have also shown the importance of high vertical resolution in the ocean mixed layer to allow coupled ocean-atmosphere processes to be faithfully represented (Bernie et al. 2005; Klingaman et al. 2009). However, increased resolution is not a universal solution for the problem of systematic model error (Slingo et al. 2003) and even the high resolution and regional models do not simulate the characteristics of daily rainfall adequately. Thus making future climate projections on local scales remains a challenge.

A potential area of improvement offered by high resolution modelling lies in resolving multi-scale interactions in the tropical monsoon regions. The importance of interactions across spatial (and temporal) scales has become increasingly apparent, not only related to large scale decadal variations setting the basic state on which ENSO operates (Meehl et al. 2001) but also on smaller scales which feed back to the large scale and mean state. As a useful example, Waliser (2006) suggested that the broad distribution of the boreal summer intraseasonal oscillation (BSISO) can modulate both the synoptic activity on smaller spatio-temporal scales as well as providing feedbacks to remote large-scale circulations. For South Asia, this is manifested in the prevalence of depressions in the monsoon trough during active periods, or over East Asia in the development of typhoons or tropical cyclones. The coupling of equatorial waves with convection and interactions with the MJO (Wheeler and Kiladis 1999) has clear implications for tropical convection, particularly our understanding of the influence of African Easterly Waves on the West African monsoon. Yang et al. (2009), amongst others, have shown that GCMs are capable of simulating convectively coupled equatorial waves, particularly when convection is situated off the equator. While interactions with the finest scales may only be possible using high resolution frameworks, perhaps in global cloud resolving models (CRMs) such as NICAM (Miura et al. 2007), several coarse-resolution coupled GCMs have been successful in describing intraseasonal convection and its propagation (Sperber et al. 2008), suggesting that high resolution is not a panacea. Results from the Year of Tropical Convection (YOTC, Moncrieff et al. 2009) will offer great opportunities in advancing knowledge of scale interactions in the tropics based on integrated observational and modelling studies.

\section{c. Aerosols}

Aerosol physics and its effect on the monsoon systems have hitherto been inadequately modelled and represent an example of missing processes. Although sulphate aerosols have been known for some time to reduce the meridional temperature gradient over South Asia (due to the direct effect of reflecting solar radiation over land areas) and thus contribute to a weaker monsoon, it is only recently that the somewhat different role of black carbon aerosols has been elucidated. Since black carbon both reflects and absorbs solar radiation, and since black carbon aerosols have only been included in the most recent generation of global coupled climate models evaluated for future climate change, their role in apparently changing the seasonality of monsoon rainfall is a relatively new concept. As noted in Section 3 above, this combination of reflection and absorption of solar radiation adds a new uncertainty to future projections of monsoon behaviour. Since these aerosols are short-lived, curtailing their production could mitigate their effects. However, cooking fires are a major source of black carbon aerosol over both Asia 
and Africa and so barring a significant change in socio-economic infrastructure, it is likely that black carbon aerosols will continue to increase over the next few decades due to rising population. Given the potential for this increased loading, and that there are other aerosol species not yet included in the models (e.g. organic aerosols), then the role of the many types of aerosols, in concert with increases of GHGs, must be delineated in new generations of global coupled ocean-atmosphere GCMs in order to more properly assess their combined role in determining the future of the monsoon.

Increasing the resolution and complexity of global GCMs as well as employing increased use of ocean-atmosphere coupling offers exciting opportunities for advancing our understanding of monsoon systems. However to be achieved it requires simultaneous progress in computational infrastructure, including data storage and transfer, as well as more optimal use of model codes that are parallelizable and easily scalable. In addition, advances in modelling will benefit from increased use of observing systems to constrain and inform our understanding of the monsoon systems.

\section{Acknowledgements}

The authors are grateful to C-P Chang for the invitation to compile this chapter. The constructive comments provided by two anonymous reviewers have helped to improve this document.

AG acknowledges the support of NOAA/Office of Global Programs grant NA07GP0213, and wishes to thank Tony Barnston.

CRM was supported by NOAA grant NA07OAR4310236.

GM was supported by the Office of Science (BER), U.S. Department of Energy Cooperative Agreement No. DE-FC02-97ER62402 and the National Science Foundation. The National Center for Atmospheric Research is sponsored by the National Science Foundation.

KS was supported under the auspices of the U.S. Department of Energy Office of Science, Climate Change Prediction Program by Lawrence Livermore National Laboratory under contract DE-AC52-07NA27344.

AT was funded by the EU-ENSEMBLES project and is a member of the NERC National Centre for Atmospheric Science.

\section{References}

Alexander, L.V., X. Zhang, T.C. Peterson, J. Caesar, B. Gleason, A.M.G. Klein Tank, M. Haylock, D. Collins, B. Trewin, F. Rahimzadeh, A. Tagipour, K. Rupa Kumar, J. Revadekar, G. Griffiths, L. Vincent, D.B. Stephenson, J. Burn, E. Aguilar, M. Brunet, M. Taylor, M. New, P. Zhai, M. Rusticucci, and J.-L. Vazquez-Aguirre (2006) Global observed changes in daily climate extremes of temperature and precipitation. Journal of Geophysical Research, 111, D05109, doi:10.1029/2005JD006290.

Allen, M. and W. Ingram (2002) Constraints on future changes in climate and the hydrological cycle. Nature, 419, 224-232.

Annamalai, H., K. Hamilton, and K.R. Sperber (2007) The South Asian summer monsoon and its relationship with ENSO in the IPCC AR4 simulations. Journal of Climate, 20, 1017-1092.

Annamalai, H. and P. Liu (2005) Response of the Asian summer monsoon to changes in El Niño properties. Quarterly Journal of the Royal Meteorological Society, 131, 805-831.

Annamalai, H., P. Liu, and S.-P. Xie (2005) Southwest Indian ocean SST variability: its local effect and remote influence on Asian monsoon. Journal of Climate, 18, 4150-4167. 
Annamalai, H. and J.M. Slingo (2001) Active/break cycles: diagnosis of the intraseasonal variability of the Asian summer monsoon. Climate Dynamics, 18, 85-102.

Arai, M. and M. Kimoto (2005) Relationship between springtime surface temperature and early summer blocking activity over Siberia. Journal of the Meteorological Society of Japan, 83, 261-267.

Arai, M. and M. Kimoto (2007) Simulated interannual variation in summertime atmospheric circulation associated with the East Asian monsoon. Climate Dynamics, 31, 435-447, doi:10.1007/s00382-007-0317-y.

Arai, M., T. Miyasaka, T. Nozawa, T. Nagashima, and M. Kimoto (2009) Effects of aerosols and greenhouse gasses on the summertime Asian monsoon rainfall trend in 20th century. (In preparation).

Ashrit, R.G., H. Douville, and K. Rupa Kumar (2003) Response of the Indian monsoon and ENSO-monsoon teleconnection to enhanced greenhouse effect in the CNRM coupled model. Journal of the Meteorological Society of Japan, 81, 779-803.

Ashrit, R.G., A. Kitoh, and S. Yukimoto (2005) Transient response of ENSO-monsoon teleconnection in MRI.CGCM2 climate change simulations. Journal of the Meteorological Society of Japan, 83, 273-291.

Bacmeister, J.T., P.J. Pegion, S.D. Schubert, and M.J. Suarez (2000) Atlas of seasonal means simulated by the NSIPP1 atmospheric GCM. NASA Tech. Memo-2000-104606.100pp.

Bader, J. and M. Latif (2003) The impact of decadal-scale Indian Ocean sea surface temperature anomalies on Sahelian rainfall and the North Atlantic Oscillation. Geophysical Research Letters, 30, doi:10.1029/2003GL018426.

Barnston, A.G., S. Li, S.J. Mason, D.G DeWitt, and L. Goddard (2009) Verification of the first 11 years of IRI's seasonal climate forecasts. Journal of Climate, submitted.

Becker, B.D., J.M. Slingo, L. Ferranti, and F. Molteni (2000) Seasonal predictability of the Indian Summer Monsoon: What role do land surface conditions play? Mausam, 52, 47-62.

Bernie, D.J., S.W. Woolnough, and J.M. Slingo (2005) Modelling diurnal and intraseasonal variability of the ocean mixed layer. Journal of Climate, 18, 1190-1202.

Biasutti, M., D.S. Battisti, and E.S. Sarachik (2003) The annual cycle over the tropical Atlantic, South America, and Africa. Journal of Climate, 16, 2491-2508.

Biasutti, M., D.S. Battisti, and E.S. Sarachik (2004) Mechanism controlling the annual cycle of precipitation in the Atlantic sector in an atmospheric GCM. Journal of Climate, 17, 4708-4723.

Biasutti, M., D.S. Battisti, and E.S. Sarachik (2005) Terrestrial influence on the annual cycle of the Atlantic ITCZ in an AGCM coupled to a slab ocean model. Journal of Climate, 18, 211228.

Black, E., J.M. Slingo, and K.R. Sperber (2003) An observational study of the relationship between excessively strong short rains in coastal East Africa and Indian Ocean SST. Monthly Weather Review, 131, 74-94.

Blanford, H.F. (1884) On the Connexion of the Himalaya Snowfall with Dry Winds and Seasons of Drought in India. Proceedings of the Royal Society of London, 37, 3-22.

Boko, M., I. Niang, A. Nyong, C. Vogel, A. Githeko, M. Medany, B. Osman-Elasha, R. Tabo, and P. Yanda (2007) Africa. Climate Change 2007: Impacts, Adaptation and Vulnerability. Contribution of Working Group II to the Fourth Assessment Report of the Intergovernmental Panel on Climate Change, Parry ML, Canziani OF, Palutikof JP, van der Linden PJ, Hanson CE (Eds.), Cambridge University Press, Cambridge UK, 433-467.

Bracco, A., F. Kucharski, F. Molteni, W. Hazeleger, and C. Severijn (2007) A recipe for simulating the interannual variability of the Asian summer monsoon and its relation with ENSO Climate Dynamics, 28, 441-460.

Burpee, R.W. (1972) The Origin and Structure of Easterly Waves in the Lower Troposphere of North Africa. Journal of the Atmospheric Sciences, 29, 77-90. 
Cavalcanti, I. and D. Herdies (2004) Data assimilation study using SALLJEX data. CLIVAR Exchanges, Vol. 9, No. 1, 23-25. International CLIVAR Project Office.

Cazes, G., A.W. Robertson, and C.R. Mechoso (2003) Seasonal dependence of ENSO teleconnections over South America and relationships with precipitation in Uruguay. Journal of Climate, 16, 1159-1176.

Charney, J. and J. Shukla (1981) Predictability of monsoons. Monsoon Dynamics, Sir J. Lighthill and R.P. Pearce (Eds.), Cambridge University Press, 99-109.

Christensen, J.H., B. Hewitson, A. Busuioc, A. Chen, X. Gao, I. Held, R. Jones, R.K. Kolli, W.T. Kwon, R. Laprise, V. Magaña Rueda, L. Mearns, C.G. Menendez, J. Raisanen, A. Rinke, A. Sarr, and P. Whetton (2007) Regional climate projections. In: S. Solomon, D. Qin, M. Manning, Z. Chen, M. Marquis, K.B. Averyt, M. Tignor, and M.L. Miller (Eds.), Climate change 2007: The Physical Science Basis. Contribution of Working Group I to the Fourth Assessment Report of the Intergovernmental Panel on Climate Change, pp 847-940.

CLIVAR Madden-Julian Oscillation Working Group, D. Waliser, K. Sperber, H. Hendon, D. Kim, E. Maloney, M. Wheeler, K. Weickmann, C. Zhang, L. Donner, J. Gottschalck, W. Higgins, I. Kang, D. Legler, M. Moncrieff, S. Schubert, W. Stern, F. Vitart, B. Wang, W. Wang, and S. Woolnough (2009) MJO Simulation Diagnostics, Journal of Climate, (in press), doi:10.1175/2008JCLI2731.1.

Cubasch, U., G.A. Meehl, G.J. Boer, R.J. Stouffer, M. Dix, A. Noda, C.A. Senior, S. Raper, and K.S. Yap (2001) Projections of future climate change. Climate Change 2001: The Scientific Basis. Contribution of Working Group I to the Third Assessment Report of the Intergovernmental Panel on Climate Change, J.T. Houghton, Y. Ding, D.J. Griggs, M. Noguer, P. van der Linden, X. Dai, K. Maskell, C.I. Johnson (Eds.), Cambridge University Press, 525582.

Dairaku, K. and S. Emori (2006) Dynamic and thermodynamic influences on intensified daily rainfall during the Asian summer monsoon under doubled atmospheric $\mathrm{CO}_{2}$ conditions. Geophysical Research Letters, 33, doi:10.1029/2005GL024754.

Doblas-Reyes, F.J., M. Deque, and J.-P. Piedelievre (2000) Multi-model spread and probabilistic seasonal forecasts in PROVOST. Quarterly Journal of the Royal Meteorological Society, 126, 2069-2087.

Douville, H. (2005) Limitations of time-slice experiments for predicting regional climate change over South Asia. Climate Dynamics, 24, 373-391.

Douville, H., J.-F. Royer, J. Polcher, P. Cox, N. Gedney, D.B. Stephenson, and P.J. Valdes (2000) Impact of $\mathrm{CO}_{2}$ doubling on the Asian summer monsoon: Robust versus modeldependent responses. Journal of the Meteorological Society of Japan, 78, 421-439.

Folland, C.K., T.N. Palmer, and D. Parker (1986) Sahel rainfall and worldwide sea temperatures, 1901-85. Nature, 320, 602-607.

Fu, X., B. Wang, D.E. Waliser, and L. Tao (2007) Impact of atmosphere-ocean coupling on the predictability of monsoon intraseasonal oscillations. Journal of the Atmospheric Sciences, 64, 157-174.

Giannini, A., M. Biasutti, I.M. Held, and A.H. Sobel (2008) A global perspective on African climate. Climatic Change, 90, 359-383, doi:10.1007/s10584-008-9396-y.

Giannini, A., R. Saravanan, and P. Chang (2003) Oceanic forcing of Sahel rainfall on interannual to interdecadal time scales. Science, 302, 1027-1030, doi:10.1126/science.1089357.

Giannini, A., R. Saravanan, and P. Chang (2005) Dynamics of the boreal summer African monsoon in the NSIPP1 atmospheric model. Climate Dynamics, 25, 517-535 doi:10.1007/s00382-005-0056-x.

Goddard, L., A.G. Barnston, and S.J. Mason (2003) Evaluation of the IRI's "Net Assessment" seasonal climate forecasts: 1997-2001. Bull. Amer. Meteor. Soc., 84, 1761-1781.

Goddard, L., and N.E. Graham (1999) Importance of the Indian Ocean for simulating rainfall anomalies over eastern and southern Africa. Journal of Geophysical Research, 104, 19099- 
19116.

Goswami, B.N. (2006) The Asian monsoon: Interdecadal variability. In "The Asian Monsoon" (Ed. B. Wang). Praxis Springer Berlin Heidelberg, pp295-327.

Grimm, A. (2003) The El Niño Impact on the Summer Monsoon in Brazil: Regional Processes versus Remote Influences. Journal of Climate, 16, 263-280.

Grimm, A.M., J.S. Pal, and F. Giorgi (2007) Connection between Spring Conditions and Peak Summer Monsoon Rainfall in South America: Role of Soil Moisture, Surface Temperature, and Topography in Eastern Brazil. Journal of Climate, 20, 5929-5945.

Gu, G. and R.F. Adler (2004) Seasonal evolution and variability associated with the West African monsoon system. Journal of Climate, 17, 3364-3377.

Gutzler, D., H.-K. Kim, W. Higgins, H. Juang, M. Kanamitsu, K. Mitchell, L. Ritchie, J.-K. Schemm, S. Schubert, R. Yang, K. Mo, Y. Song, and P. Pegion (2003) The North American monsoon Model Assessment Project (NAMAP). NCEP/Climate Prediction Center ATLAS No. 11, 32pp.

Hagos, S.M. and K.H. Cook (2008) Ocean Warming and Late 20th Century Sahel Drought and Recovery. Journal of Climate, 21, 3797-3814.

Held, I.M., T.L. Delworth, J. Lu, K. Findell, and T.R. Knutson (2005) Simulation of Sahel drought in the 20th and 21st centuries. Proceedings of the National Academy of Science, 102, 17891-17896, doi:10.1073/pnas.0509057102.

Held, I. and B. Soden (2006) Robust responses of the hydrological cycle to global warming. Journal of Climate, 19, 5686-5699.

Higgins, R.W., A. Douglas, A. Hahmann, E.H. Berbery, D. Gutzler, J. Shuttleworth, D. Stensrud, J. Amador, R. Carbone, R. Lobato, M. Cortez, M. Douglas, R. Lobato, J. Meitin, Ch. Ropelewski, J. Schemm, S. Schubert, and Ch. Zhang (2003) Progress in Pan American CLIVAR Research: The North American Monsoon System. Atmosfera, 16, 29-65.

Hirota, N., M. Takahashi, N. Sato, and M. Kimoto (2005) Change of the Baiu Season Climate in the East Asia During 1979 to 2003. SOLA, 1, 137-140, doi:10.2151/sola.2005-036.

Hoerling, M.P., J.W. Hurrell, J. Eischeid, and A.S. Phillips (2006) Detection and attribution of 20th century northern and southern African monsoon change. Journal of Climate, 19, 39894008.

Hu, Z.-Z., M. Latif, E. Roeckner, and L. Bengtsson (2000) Intensified Asian summer monsoon and its variability in a coupled model forced by increasing greenhouse gas concentrations. Geophysical Research Letters, 27, 2681-2684.

Janicot, S., V. Moron, and B. Fontaine (1996) Sahel droughts and ENSO dynamics. Geophysical Research Letters, 23, 515-518.

Jhun, J.-G. and E.-J. Lee (2004) A new East Asian winter monsoon index and associated characteristics of winter monsoon. Journal of Climate, 17, 711-726.

Ju, J. and J. Slingo (1995) The Asian summer monsoon and ENSO. Quarterly Journal of the Royal Meteorological Society, 121, 1133-1168.

Kalnay, E., M. Kanamitsu, R. Kistler, W. Collins, D. Deaven, L. Gandin, M. Iredell, S. Saha, G. White, J. Woollen, Y. Zhu, A. Leetmaa, R. Reynolds, M. Chelliah, W. Ebisuzaki, W. Higgins, J. Janowiak, K.C. Mo, C. Ropelewski, J. Wang, Roy Jenne, and Dennis Joseph (1996) The NCEP-NCAR 40-year reanalysis project. Bulletin of the American Meteorological Society, 77, 437-471.

Kang, I.-S., K. Jin, B. Wang, K.-M. Lau, J. Shukla, V. Krishnamurthy, S.D. Schubert, D.E. Wailser, W.F. Stern, A. Kitoh, G.A. Meehl, M. Kanamitsu, V.Y. Galin, V. Satyan, C.-K. Park, and Y. Liu (2002) Intercomparison of the climatological variation of Asian summer monsoon precipitation simulated by 10 GCMs. Climate Dynamics, 19, 383-395.

Kawatani, Y. and M. Takahashi (2003) Simulation of the Baiu front in a High resolution GCM. Journal of the Meteorological Society of Japan, 81, 113-126. 
Kemball-Cook, S. and B. Wang (2001) Equatorial Waves and Air-Sea Interaction in the Boreal Summer Intraseasonal Oscillation, Journal of Climate, 14, 2923-2942.

Kharin, V.V., F.W. Zwiers, X. Zhang and G.C. Hegerl (2007) Changes in Temperature and Precipitation Extremes in the IPCC Ensemble of Global Coupled Model Simulations. Journal of Climate, 20, 1419-1444, doi:10.1175/JCLI4066.1.

Kimoto, M. (2005) Simulated change of the East Asian circulation under the global warming Scenario. Geophysical Research Letters, 32, L16701, doi:10.1029/2005GL023383.

Kirtman, B. and A. Pirani (2008) WCRP position paper on seasonal prediction. WCRP Informal Report No. 3/2008, ICPO Publication No. 127, 24pp.

Kitoh, A. and S. Kusunoki (2008) East Asian summer monsoon simulation by a $20-\mathrm{km}$ mesh AGCM. Climate Dynamics, 31, 389-401, doi:10.1007/s00382-007-0285-2.

Kobayashi, C and M. Sugi (2004) Impact of horizontal resolution on the simulation of the Asian summer monsoon and tropical cyclones in the JMA global model. Climate Dynamics, 93, 165-176, doi:10.1007/s00382-004-0427-8.

Kodera, K. and M. Chiba (1989) West Siberian spring snow cover and East Asian June 500hPa Height. Papers in Meteorology and Geophysics, 40, 51-54.

Kosaka, Y. and H. Nakamura (2006) Structure and dynamics of the summertime PacificJapan teleconnection pattern. Quarterly Journal of the Royal Meteorological Society, 132, 2009-2030, doi:10.1256/qj.05.204.

Klingaman, N.P., H. Weller, S.J. Woolnough, P.M. Inness, and J.M. Slingo (2009) Coupled simulations of the Indian monsoon intraseasonal oscillation using a fine-resolution mixedlayer ocean model. Proceedings of the ECMWF Workshop on Ocean-Atmosphere Interactions, 10-12 November 2008, 195-205.

Krishna Kumar, K., B. Rajagopalan, and M.A. Cane (1999) On the weakening relationship between the Indian monsoon and ENSO. Science, 284, 2156-2159.

Kusunoki, S., J. Yoshimura, H. Yoshimiura, A. Noda, K. Oouchi, and R. Mizuta (2006) Change of Baiu rain band in global warming projection by an atmospheric general circulation model with a 20-km grid size. Journal of the Meteorological Society of Japan, 84, 581-611.

Lamb, P.J. (1982) Persistence of Subsaharan drought. Nature, 299, 46-48.

Lau, K.M., M.K. Kim, and K.M. Kim (2006) Asian summer monsoon anomalies induced by aerosol direct forcing: The role of the Tibetan Plateau. Climate Dynamics, 26, 855-864.

Lau, N.-C. and M.J. Nath (2000) Impact of ENSO on the variability of the Asian-Australian monsoons as simulated in GCM experiments. Journal of Climate, 13, 4287-4309.

Lebel, T., A. Diedhiou, and H. Laurent (2003) Seasonal cycle and interannual variability of the Sahelian rainfall at hydrological scales. Journal of Geophysical Research, doi:10.1029/2001JD001580.

Lei, Y., B.J. Hoskins, and J.M. Slingo (2009) Exploring the interplay between natural decadal variability and anthropogenic climate change in Chinese summer rainfall. Part 2: Internal variability in a 1000-year control simulation Quarterly Journal of the Royal Meteorological Society, (in preparation).

Lin J.L., K.M. Weickmann, G.N. Kiladis, B.E. Mapes, S.D. Schubert, M.J. Suarez, J.T. Bacmeister, and M.I. Lee (2008) Subseasonal Variability Associated with Asian Summer Monsoon Simulated by 14 IPCC AR4 Coupled GCMs. Journal of Climate, 21, 4541-4567, doi:10.1175/2008JCLI1816.1.

Loschnigg, J.G. and P.J. Webster (2000) A coupled ocean-atmospheric system of SST regulation for the Indian Ocean. Journal of Climate, 13, 3342-3360.

Lu, J. and T.L. Delworth (2005) Oceanic forcing of late 20th century Sahel drought. Geophysical Research Letters, 32, L22706, doi:10.1029/2005GL023316.

Lyon, B. and S.J. Mason (2007) The 1997-98 Summer Rainfall Season in Southern Africa Part I: Observations. Journal of Climate, 20, 5134-5148. 
Ma, H.-Y. and C.R. Mechoso (2007) Submonthly Variability in the South American Monsoon System. Journal of the Meteorological Society of Japan, 85, 385-401.

Mandke, S.K., A.K. Sahai, M.A. Shinde, S. Joseph, and R. Chattopadhyay (2007) Simulated changes in active/break spells during the Indian summer monsoon due to enhanced $\mathrm{CO}_{2}$ concentrations: assessment from selected coupled atmosphere-ocean global climate models. International Journal of Climatology, 27, 837-859.

Mason, S.J. (2001) El Niño, climate change, and southern African climate. Environmetrics, 12, 327-345.

Matthews, A.J. (2004) Intraseasonal variability over tropical Africa during northern summer. Journal of Climate, 17, 2427-2440, doi:10.1175/15200442(2004)017<2427:IVOTAD>2.0.CO;2.

May, W. (2004) Simulation of the variability and extremes of daily rainfall during the Indian summer monsoon for present and future times in a global time-slice experiment. Climate Dynamics, 22, 183-204.

Mechoso, C.R., A.W. Robertson, C.F. Ropelewski, and A.M. Grimm (2005) The American Monsoon Systems: An Introduction. The Global Monsoon System: Research and Forecast. C.-P. Chang, B. Wang and N.-C.G. Lau (Eds.), WMO/TD No. 1266 (TMRP Report No. 70), 197-206.

Meehl G.A., R. Lukas, G.N. Kiladis, K.M. Weickmann, A.J. Matthews, and M. Wheeler (2001) A conceptual framework for time and space scale interactions in the climate system. Climate Dynamics, 17, 753-775, doi:10.1007/s003820000143.

Meehl, G.A. and J.M. Arblaster (2003) Mechanisms for projected future changes in south Asian monsoon precipitation. Climate Dynamics, 21, 659-675.

Meehl, G.A., J.M. Arblaster, and W.D. Collins (2008) Effects of black carbon aerosols on the Indian monsoon. Journal of Climate, 21, 2869-2882.

Meehl, G.A., T.F. Stocker, W.D. Collins, P. Friedlingstein, A.T. Gaye, J.M. Gregory, A. Kitoh, R. Knutti, J.M. Murphy, A. Noda, S.C.B. Raper, I.G. Watterson, A.J. Weaver, and Z.-C. Zhao (2007) Global Climate Projections. In: Climate Change 2007: The Physical Science Basis. Contribution of Working Group I to the Fourth Assessment Report of the Intergovernmental Panel on Climate Change [Solomon, S., D. Qin, M. Manning, Z. Chen, M. Marquis, K.B. Averyt, M. Tignor and H.L. Miller (Eds.)]. Cambridge University Press, Cambridge, United Kingdom and New York, NY, USA.

Mekonnen, A., C.D. Thorncroft, A.R. Aiyyer, and G.N. Kiladis (2008) Convectively coupled Kelvin waves over tropical Africa during the boreal summer: structure and variability. Journal of Climate, 21, 6649-6667.

Miura, H., M. Satoh, T. Nasuno, A.T. Noda, and K. Oouchi (2007) A Madden-Julian Oscillation Event Realistically Simulated by a Global Cloud-Resolving Model. Science, 318, 1763, doi:10.1126/science.1148443.

Mo, K.C., J.K. Schemm, H.M.H. Juang, R.W. Higgins, and Y. Song (2005) Impact of model resolution on the prediction of summer precipitation over the United States and Mexico. Journal of Climate, 18, 3910-3927.

Moncrieff, M.W., D.E. Waliser, and M.A. Shapiro (2009) The multi-scale organization of tropical convection and its interaction with the global circulation: Year of Tropical Convection (YOTC). Bulletin of the American Meteorological Society, (submitted).

Moron, V., A.W. Robertson, M.N. Ward, and O. Ndiaye (2008a) Weather Types and Rainfall over Senegal. Part I: Observational Analysis. Journal of Climate, 21, 266-287, doi:10.1175/2007JCLI1601.1.

Moron, V., A.W. Robertson, M.N. Ward, and O. Ndiaye (2008b) Weather Types and Rainfall over Senegal. Part II: Downscaling of GCM Simulations. Journal of Climate, 21, 288-307, doi:10.1175/2007JCLI1624.1. 
Mounier, F., S. Janicot, and G.N. Kiladis (2007) Analysis of the dominant mode of convectively coupled Kelvin waves in the West African monsoon. Journal of Climate, 20, 1487-1503, doi:10.1175/JCLI4059.1.

Neelin, J.D., C. Chou, and H. Su (2003) Tropical drought regions in global warming and El Niño teleconnections. Geophysical Research Letters, 30, 2275, doi:10.1029/2003GL0018625.

Nicholson, S.E. (1993) An overview of African rainfall fluctuations of the last decade. Journal of Climate, 6, 1463-1466.

Nicholson, S.E. and P.J. Webster (2007) A physical basis for the interannual variability of rainfall in the Sahel. Quarterly Journal of the Royal Meteorological Society, 133, 2065-2084, doi:10.1002/qj.104.

Ninomiya, K. (2004) Large-and mesoscale features of Meiyu-Baiu front associated with intense rainfalls. East Asian Monsoon. Ed. by C.P. Chang, World Scientific Series on Meteorology of East Asia, Vol. 2, 404-435.

Ninomiya, K. and T. Murakami (1987) The early summer rainy season (Baiu) over Japan. Monsoon Meteorology, Ed. by C.-P. Chang and T.N. Krishnamurti, Oxford Univ. Press, 93121.

Nitta, T. (1987) Convective activities in the tropical western Pacific and their impact on the Northern Hemisphere summer circulation. Journal of the Meteorological Society of Japan, 65, 373-390.

Nogués-Paegle, J., C.R. Mechoso, R. Fu, E.H. Berbery, W.C. Chao, T.-C. Chen, K. Cook, A.F. Diaz, D. Enfield, R. Ferreira, A.M. Grimm, V. Kousky, B. Liebmann, J. Marengo, K. Mo, J.D. Neelin, J. Paegle, A.W. Robertson, A. Seth, C.S. Vera, and J. Zhou (2002) Progress in Pan American CLIVAR Research: Understanding the South American Monsoon. Meteorologica, 27, 3-30.

Ogallo, L.J. (1989) The spatial and temporal patterns of the East African seasonal rainfall derived from principal component analysis. International Journal of Climatology, 9, 145-167.

Palmer, T.N., A. Alessandri, U. Andersen, P. Cantelaube, M. Davey, P. Délécluse, M. Déqué, E. Díez, F.J. Doblas-Reyes, H. Feddersen, R. Graham, S. Gualdi, J.-F. Guérémy, R. Hagedorn, M. Hoshen, N. Keenlyside, M. Latif, A. Lazar, E. Maisonnave, V. Marletto, A. P. Morse, B. Orfila, P. Rogel, J.-M. Terres, and M.C. Thomson (2004) Development of a European multimodel ensemble system for seasonal-to-interannual prediction (DEMETER). Bulletin of the American Meteorological Society, 85, 853-872.

Pant, G.B. and K. Rupa Kumar (1997) Climates of South Asia. John Wiley \& Sons, 320pp.

Ramanathan, V., C. Chung, D. Kim, T. Bettge, L. Buja, J.T. Kiehl, W.M. Washington, Q. Fu, D.R. Sikka, and M. Wild (2005) Atmospheric brown clouds: Impacts on South Asian climate and hydrological cycle. Proceedings of the National Academy of Science, 102, 5326-5333.

Reason, C.J.C. and D. Jagadheesha (2005) A model investigation of recent ENSO impacts over southern Africa. Meteorology And Atmospheric Physics, 89, 181-205.

Rodwell, M.J. and B.J. Hoskins (1995) A Model of the Asian Summer Monsoon. Part II: Cross-Equatorial low and PV Behavior. Journal of the Atmospheric Sciences 52, 1341-1356.

Ropelewski, C.F., D. Gutzler, E.W. Higgins, and C.R. Mechoso (2004) The North American Monsoon Systems. The Global Monsoon System: Research and Forecast. C.-P. Chang, B. Wang and N.-C. G. Lau (Eds.), WMO/TD No. 1266 (TMRP Report No. 70), 207-218.

Rupa Kumar, K., A.K. Sahai, K. Krishna Kumar, S.K. Patwardhan, P.K. Mishra, J.V. Revadekar, K. Kamala, and G.B. Pant (2006) High resolution climate change scenarios for India for the 21st century. Current Science, 90, 334-345.

Schreck, C.J. and F.H.M. Semazzi (2004) Variability of the recent climate of eastern Africa. International Journal of Climatology, 24, 681-701.

Shen, X., M. Kimoto, and A. Sumi (1998) Role of Land Surface Processes Associated with Interannual Variability of Broad-scale Asian Summer Monsoon as Simulated by the CCSR/NIES AGCM. Journal of the Meteorological Society of Japan, 76, 217-236. 
Shukla, J. and Y. Mintz (1982) Influence of Land-Surface Evapotranspiration on the Earth's Climate. Science, 215, 1498-1501.

Slingo, J.M. and H. Annamalai (2000) 1997: The El Niño of the century and the response of the Indian summer monsoon. Monthly Weather Review, 128, 1778-1797.

Slingo, J., P. Inness, R. Neale, S. Woolnough, and G.Y.-Yang (2003) Scale interactions on diurnal to seasonal timescales and their relevance to model systematic errors. Annals of Geophysics, 46, 139-155.

Slingo, J., H. Spencer, B. Hoskins, P. Berrisford, and E. Black (2005) The meteorology of the Western Indian Ocean, and the influence of the East African Highlands. Philosophical Transactions of the Royal Society A, 363, 25-42, doi:10.1098/rsta.2004.1473.

Sperber, K.R. and H. Annamalai (2008) Coupled model simulations of boreal summer intraseasonal (30-50 day) variability, Part I: systematic errors and caution on use of metrics. Climate Dynamics, 31, 345-372.

Sperber, K.R., C. Brankovic, M. Deque, C.S. Fredericksen, R. Graham, A. Kitoh, C. Kobayashi, T. Palmer, K. Puri, W. Tennent, and E. Volodin (2001) Dynamical seasonal predictability of the Asian summer monsoon. Monthly Weather Review, 129, 2226-2248.

Sperber, K.R., S. Hameed, G.L. Potter, and J.S. Boyle (1994) Simulation of the northern summer monsoon in the ECMWF model: sensitivity to horizontal resolution. Monthly Weather Review, 122, 2461-2481.

Sperber, K.R. and T.N. Palmer (1996) Interannual tropical rainfall variability in general circulation model simulations associated with the Atmospheric Model Intercomparison Project. Journal of Climate, 9, 2727-2750.

Sperber, K.R., J.M. Slingo, and H. Annamalai (2000) Predictability and the relationship between subseasonal and interannual variability during the Asian summer monsoon. Quarterly Journal of the Royal Meteorological Society, 126, 2545-2574.

Sperber, K.R., J.M. Slingo, D.E. Waliser, and P.M. Inness (2008) Coarse-resolution models only partly cloudy. Comment on "A Madden-Julian oscillation event simulated by a global cloud-resolving model" by Miura et al. Science, 320, 612 .

Sultan, B. and S. Janicot (2003) The West African monsoon dynamics. Part II: the "preonset" and "onset" of the summer monsoon. Journal of Climate, 16, 3407-3427.

Sun Y., S. Solomon, A. Dai, and R.W. Portman (2006) How often does it rain? Journal of Climate, 19, 916-934, doi:10.1175/JCLI3672.1.

Tanaka, H.L., N. Ishizaki, and D. Nohara (2005) Intercomparison of the intensities and trends of Hadley, Walker and monsoon circulations in the global warming projections. SOLA, 1, 7780.

Ting, M., Y. Kushnir, R. Seager, and C. Li (2009) Forced and Internal Twentieth-Century SST Trends in the North Atlantic. Journal of Climate, 22, 1469-1481, doi:10.1175/2008JCLI2561.1.

Tippett, M.K. (2006) Filtering of GCM simulated Sahel precipitation. Geophysical Research Letters 33, L01804, doi:10.1029/2005GL024923.

Trenberth, K., P.D. Jones, P. Ambenje, R. Bojariu, D. Easterling, A. Klein Tank, D. Parker, F. Rahimzadeh, J.A. Renwick, M.B.S. Rusticucci, and P. Zhai (2007) Observations: surface and atmospheric climate change. In: S. Solomon, D. Qin, M. Manning, Z. Chen, M. Marquis, K.B. Averyt, M. Tignor, and M.L. Miller (Eds.) Climate change 2007: the physical science basis. Contribution of Working Group I to the Fourth Assessment Report of the Intergovernmental Panel on Climate Change. Cambridge Univ. Press, Cambridge, UK, pp 235-336.

Turner, A.G., P.M. Inness, and J.M. Slingo (2005) The role of the basic state in the ENSOmonsoon relationship and implications for predictability. Quarterly Journal of the Royal Meteorological Society, 131, 781-804.

Turner, A.G., P.M. Inness, and J.M. Slingo (2007) The effect of doubled $\mathrm{CO}_{2}$ and model basic state biases on the monsoon-ENSO system. I: Mean response and interannual variability. Quarterly Journal of the Royal Meteorological Society, 133, 1143-1157. 
Turner, A.G. and J.M. Slingo (2009a) Subseasonal extremes of precipitation and active-break cycles of the Indian summer monsoon in a climate change scenario. Quarterly Journal of the Royal Meteorological Society, 135, 549-567, doi:10.1002/qj.401.

Turner, A.G. and J.M. Slingo (2009b) Uncertainties in future projections of extreme precipitation in the Asian monsoon regions. Atmospheric Science Letters, 10 doi:10.1002/asl.223.

Ueda, H., A. Iwai, K. Kuwako, and M.E. Hori (2006) Impact of anthropogenic forcing on the Asian summer monsoon as simulated by eight GCMs. Geophysical Research Letters, 33, L06703.

van Oldenborgh, G.-J., M.A. Balmaseda, L. Ferranti, T.N. Stockdale, and D.L.T. Anderson (2005) Did the ECMWF seasonal forecast model outperform statistical ENSO forecast models over the last 15 years? Journal of Climate, 18, 3240-3249.

Vera, C., W. Higgins, J. Amador, T. Ambrizzi, P.L. Silva Dias, R. Garreaud, D. Gochis, D. Gutzler, D. Lettenmaier, J. Marengo, C.R. Mechoso, J. Nogues-Paegle, and C. Zhang (2006a) Towards a Unified View of the American Monsoon Systems. Journal of Climate, 19, 4977-5000.

Vera, C., G. Silvestri, B. Liebmann, and P. Gonzalez (2006b) Climate change scenarios for seasonal precipitation in South America from IPCC-AR4 models. Geophysical Research Letters, 33, L13707, doi:10.1029/2006GL025759.

Waliser, D.E. (2006) Intraseasonal variability. In "The Asian Monsoon" (Ed. B. Wang). Praxis Springer Berlin Heidelberg, pp. 203-257.

Waliser, D.E., K. Weickmann, R. Dole, S. Schubert, O. Alves, C. Jones, M. Newman, H.-L. Pan, A. Roubicek, S. Saha, C. Smith, H. Van den Dool, F. Vitart, M. Wheeler, and J. Whitaker (2006) The experimental MJO prediction project. Bulletin of the American Meteorological Society, 87, 425-431.

Waliser, D.E., W. Stern, S. Schubert, and K.-M. Lau (2003) Dynamic predictability of intraseasonal variability associated with the Asian summer monsoon. Quarterly Journal of the Royal Meteorological Society, 129, 2897-2925.

Walker, G.T. (1924) Correlation in seasonal variations of weather, IV, A further study of world weather. Memoirs of the Indian Meteorological Department, 24, 275-332.

Walker, J. and P.R. Rowntree (1977) The effect of soil moisture on circulation and rainfall in a tropical model. Quarterly Journal of the Royal Meteorological Society, 103, 29-46.

Wang, B., Q. Bao, B. Hoskins, G. Wu, and Y. Liu (2008a) Tibetan Plateau warming and precipitation change in East Asia. Geophysical Research Letters, 35, L14702, doi:10.1029/2008GL034330.

Wang, B., Q. Ding, X. Fu, I.-S. Kang, K. Jin, J. Shukla, and F. Doblas-Reyes (2005) Fundamental challenges in simulation and prediction of summer monsoon rainfall. Geophysical Research Letters, 32(15), L15711, doi:10.1029/2005GL022734.

Wang, B., I.-S. Kang, and J.Y. Lee (2004) Ensemble simulations of Asian-Australian monsoon variability by 11 AGCMs. Journal of Climate, 17, 803-818.

Wang, B., J.-Y. Lee, I.-S. Kang, J. Shukla, C.-K. Park, A. Kumar, J. Schemm, S. Cocke, J.-S. Kug, J.-J. Luo, T. Zhou, B. Wang, X. Fu, W.-T. Yun, O. Alves, E. K. Jin, J. Kinter, B. Kirtman, T. Krishnamurti, N. C. Lau, W. Lau, P. Liu, P. Pegion, T. Rosati, S. Schubert, W. Stern, M. Suarez, and T. Yamagata (2009) Advance and prospectus of seasonal prediction: assessment of the APCC/CliPAS 14-model ensemble retrospective seasonal prediction (1980-2004). Climate Dynamics, 33, 93-117, doi:10.1007/s00382-008-0460-0.

Wang, B., R. Wu, and X. Fu (2000) Pacific-East Asian teleconnection: How does ENSO affect East Asian climate? Journal of Climate, 13, 1517-1536.

Wang, B., R. Wu, and T. Li (2003) Atmosphere-warm ocean interaction and its impacts on the Asian-Australian monsoon variation. Journal of Climate, 16, 1195-1211. 
Wang, B., J. Yang, T. Zhou, and B. Wang (2008b) Interdecadal Changes in the Major Modes of Asian-Australian Monsoon Variability: Strengthening Relationship with ENSO since the Late 1970s. Journal of Climate, 21, 1771-1789, doi:10.1175/2007JCLI1981.1.

Ward, M.N. (1998) Diagnosis and short-lead time prediction of summer rainfall in tropical north Africa at interannual and multidecadal timescales. Journal of Climate, 11, 3167-3191.

WCRP (1992) Simulation of interannual and intraseasonal monsoon variability. (Report of Workshop, Boulder, CO, U.S.A., 21-24 October 1991). WCRP-68, WMP/TD-470, WCRP, Geneva, Switzerland, $231 \mathrm{pp}$.

WCRP (1993) Simulation and prediction of monsoons: Recent results (TOGAWGNE Monsoon). Numerical Experimentation Group (New Delhi, India, 12-14 January 1993). WCRP-80, WMP/TD-546, WCRP, Geneva, Switzerland, 82pp.

Webster, P.J. and C. Hoyas (2004) Prediction of monsoon rainfall and river discharge on 1530 day time scales. Bulletin of the American Meteorological Society, 85, 1745-1765.

Webster, P.J., V.O. Magaña, T.N. Palmer, J. Shukla, R.A. Tomas, M. Yanai, and T. Yasunari (1998) Monsoons: Processes, predictability, and the prospects for prediction. Journal of Geophysical Research, 103(C7), 14451-14510.

West, C.T., C. Roncoli, and F. Ouattara (2008) Local perceptions and regional climate trends of the Central Plateau of Burkina Faso. Land Degradation \& Development, 19, 289-304, doi:10.1002/ldr.842.

Wheeler, M. and G.N. Kiladis (1999) Convectively Coupled Equatorial Waves: Analysis of Clouds and Temperature in the Wavenumber-Frequency Domain. Journal of the Atmospheric Sciences, 56, 374-399.

Wheeler, M. and K.M. Weickmann (2001) Real-time monitoring and prediction of modes of coherent synoptic to intraseasonal tropical variability. Monthly Weather Review, 129, 26772694.

Wu, G., Y. Liu, T. Wang, R. Wan, X Liu, W. Li, Z Wang, Q. Zhang, A. Duan, and X. Liang (2007) The Influence of Mechanical and Thermal Forcing by the Tibetan Plateau on Asian Climate. Journal of Hydrometeorology, 8, 770-789.

Wu, R. and B. Wang (2002) A Contrast of the East Asian Summer Monsoon and ENSO Relationship between 1962-1977 and 1978-1993. Journal of Climate, 15, 3266-3279.

Xue, Y., F. de Sales, W.-P. Li, C.R. Mechoso, C.A. Nobre, and H.-M. Juang (2006) Role of land surface processes in South American monsoon development. Journal of Climate, 19, 741-762.

Yang, G.-Y., J. Slingo, and B. Hoskins (2009) Convectively Coupled Equatorial Waves in High-Resolution Hadley Centre Climate Models. Journal of Climate, 22, 1897-1919, doi:10.1175/2008JCLI2630.1.

Yasunari, T., A. Kitoh, and T. Tokioka (1991) Local and Remote Responses to Excessive Snow Mass over Eurasia Appearing in the Northern Spring and Summer Climate - A Study with the MRI GCM. Journal of the Meteorological Society of Japan, 69, 473-486.

Zamboni, L., C.R. Mechoso, and F. Kucharski (2009) Empirical and Numerical seasonal predictions of precipitation over South East South America. Geophysical Research Letters, (in preparation). 